\title{
Treating a Mother's Accommodation Behaviors of Her Adult Son's OCD: The Case of "Brianne" and "Charlie"
}

\author{
JAMES MARINCHAK ${ }^{\mathrm{a}, \mathrm{b}}$ \\ a Anxiety Disorders Clinic, Rutgers - The State University of New Jersey \\ b Correspondence regarding this article should be addressed to James Marinchak, Anxiety Disorders Clinic, 797 \\ Hoes Lane West, Piscataway, NJ 08854-8020 \\ Email: jamma789@yahoo.com
}

\begin{abstract}
Obsessive-compulsive disorder (OCD) is an anxiety disturbance in which distress and impairment extend beyond the patient to their immediate family members. Many family members become involved in their loved one's compulsions by engaging in accommodation behaviors, which ultimately make it easier to perform compulsions or avoid obsession-invoking triggers, frequently exacerbating the severity of the OCD symptoms and decreasing motivation for treatment. Also, accommodation behaviors can indirectly result in negative consequences for the family member engaging in them and for other non-OCD members of the family, reducing their quality-of-life. The current case study documents and discusses a 3-month, 10-session, cognitive-behavioral treatment designed to help "Brianne," a married Caucasian mother of two in her 40s, reduce her accommodation behaviors with her 19-year-old son, "Charlie," who was unmotivated to accept treatment for his diagnosed OCD and who was living at home. In line with the above, the treatment was premised on the hypothesis that reducing Brianne's accommodation behaviors would have a positive impact not only on Charlie and Brianne, but also on the other two members of Brianne's nuclear family: her husband "Jack," and her older son "Shane." The therapy focused on (a) providing Brianne with psychoeducation regarding the nature of OCD and the negative impact of accommodation behaviors, (b) developing Brianne's alternative coping behaviors in response to Charlie's rituals, (c) offering Brianne communication training, and (d) promoting Brianne's self-care behaviors. Results indicate that the treatment was effective in reducing Brianne's accommodation and improving her quality of life as well as her husband's and other son's within the household, but that more treatment was likely necessary in order to consolidate therapeutic gains. The treatment did not appear to impact Charlie's OCD treatmentseeking motivation nor his levels of anxiety or aggressive outbursts by the end of therapy. Factors contributing to the results of the treatment are discussed. Overall, the case results suggest that family members living with OCD-diagnosed adults not currently seeking treatment can derive benefit from a brief intervention designed to reduce accommodation behaviors, improve family communication, and promote self-care.
\end{abstract}

Key words: obsessive compulsive disorder (OCD); family accommodation behavior; family systems; cognitive-behavioral treatment; case study; clinical case study 
Treating a Mother's Accommodation Behaviors of Her Adult Son's OCD:

Pragmatic Case Studies in Psychotherapy, http://pcsp.libraries.rutgers.edu

Volume 9, Module 1, Article 1, pp. 1-57, 02-17-13 [copyright by author]

\section{CASE CONTEXT AND METHOD}

\section{Introduction}

Obsessive compulsive disorder (OCD) is an anxiety disorder characterized by the presence of repetitive, unwanted and distressing thoughts and/or ritualistic behaviors and thought processes designed to reduce distress (American Psychiatric Association [APA], 2000). OCD is a fairly common disorder, with a current prevalence rate between 1-4\% in both child and adult populations (Weissman et al., 1994; Zohar, 1999). An individual with OCD is likely to experience significant functional impairment and a reduced quality of life. Children and adults with OCD often experience disruption and strain on their family and peer relationships along with significant difficulty functioning in academic and work environments (Cooper, 1996; Koren, Thienemann, \& Davenport, 1996; Piacentini, Bergman, Keller, \& McCracken, 2003). Examples of such disruptions can include conflict between family members and friends, difficulty maintaining concentration on task assignments, and in more severe cases extreme difficulty functioning in environments that trigger anxiety and an associated urge to perform rituals. OCD also appears to be a chronic condition, with a typical onset in childhood (Rasmussen \& Eisen, 1992) with symptoms continuing into adulthood unremittant, without therapeutic intervention (Livingston-Van Noppen et al., 1990).

The disturbances engendered by OCD symptoms appear to extend beyond the identified patient to their immediate family as well. There have been a variety of studies examining the impact of living in a household with an OCD family member (e.g. Albert et al., 2007; Geffken et al., 2010; Steketee, 1997). The results of these studies show family units attempting to cope with OCD are likely to experience relationship strains characterized by negative feelings such as frustration, hostility and hopelessness, financial distress, and time sacrifices (Geffken et al., 2006; Magliano, Tosini, Guarneri, Marasco, \& Catapano, 1996). In an extensive survey of family members of adults with OCD, Cooper (1996) found 75\% of respondents indicated their quality of life had been disrupted as a result of OCD. Some of the most common examples of these disruptions were reporting the loss of valued personal relationships and previously enjoyed leisure activities. Additionally, family members of individuals with OCD over the age of 18 may experience feelings of frustration and hopelessness if their loved one is unwilling to enter into treatment. This is due to the fact that the law in many states does not allow parents to enter their children into mental health treatment once they are legally considered to be an adult. Given these impacts, it is not surprising that family members may themselves begin to experience their own psychological distress, particularly when feeling hopeless about the possibility of the family's situation ever improving (Geffken et al., 2006). The present case study illustrates these themes as they play out in the life of "Brianne" and her adult son "Charlie" who has diagnosed OCD but resists treatment.

\section{Research Context of the Case}

This case was a pilot study for a larger research project on reducing family accommodation. In line with this, using the general procedures described below, the study began with a plan to recruit a single adult, non-treatment motivated, OCD individual and one primary 
adult relative who was currently residing in the same household. The OCD-family dyad was to be recruited either through contact initiated through the general information line of a local anxiety clinic or through participation in one of two local OCD support groups for family members of individuals with OCD associated with the clinic. Recruitment was initially conducted through the non-OCD primary family member who was inquiring into treatment options, soliciting treatment services for their adult treatment-resistant OCD family member, or seeking therapy for themselves to cope with family member's OCD. All treatment will be conducted at the anxiety clinic by the primary investigator who received clinical supervision throughout the study by a senior licensed clinical psychologist with expertise in treating OCD.

\section{$\underline{\text { Specific Selection Procedures for a Patient }}$}

Based on definitions from previous research on OCD treatment involving family members (Chambless \& Steketee, 1999), both family members must have lived together for at least three months prior to initial contact and intend to continue doing so over the duration of the study. Additionally, a hierarchy of importance was utilized in the selection of primary family member for inclusion in the treatment, whereby (a) spouses/domestic partners will be chosen over other relatives; (b) if the OCD patient is single, a parent will be chosen over other relatives; (c) when two parents are present, the parent contacting the treatment clinic or attending the support group will be selected; (d) if no parents or spouses/partners are present, the individual contacting the treatment clinic or attending the support group will be selected.

Inclusion criteria for the adult patient with OCD consisted of being between 18 and 50 years of age, having a primary diagnosis of OCD of at least mild severity with symptoms present at least one year, not receiving current psychiatric or psychological treatment for their OCD and a low motivation to pursue such treatments at the onset of the study. Exclusion criteria for the OCD patient included current or past diagnosis of psychosis, current suicidality, and a current diagnosis of alcohol or drug dependence.

Inclusion criteria for the primary family member consisted of being between 18 and 65 years of age, no current or past diagnosis of OCD, and no current psychological treatment for distress related to their relationship with their OCD relative and a desire to see their loved one receive mental health services for their OCD. Exclusion criteria for the family member will be the same as exclusion criteria for the OCD patient along with not meeting current criteria for OCD.

\section{$\underline{\text { Assessment Procedures }}$}

Initially, the primary family member selected was screened via telephone by the principal investigator to determine preliminary eligibility for themselves and their adult OCD relative. Upon passing this screen and agreeing to participate, the principal investigator spoke with the OCD relative over the phone and explained the nature and procedure of the study. Upon agreement to participate, an independent diagnostic interview (the Anxiety Disorders Interview Schedule Adult Version, Client Interview Schedule [ADIS-IV; Brown, DiNardo, \& Barlow, 1994]) was scheduled in the family's home for both the primary family member determined to 
enter treatment and the OCD relative. The purpose of the interview was to determine final diagnostic eligibility, obtain both participants' written informed consent, and collect baseline self-report measures. The primary family member and OCD relative were separately interviewed by the principal investigator to ensure confidentiality. Additionally, family members were asked to fill out self-report forms privately (see section below for a description of the measures) and return them to the principal investigator in a sealed envelope, ensuring that neither family member has access to the other's responses.

At the completion of the treatment phase, both the primary family member and the OCD relative again received the same comprehensive in-home diagnostic interview and battery of selfreport measures that were administered prior to the beginning of treatment. The data collection procedure was identical to the pre-treatment assessment for both family members.

\section{Assessment Measures Employed to Assess Charlie's Psychopathology and Motivation for Treatment}

Anxiety Disorders Interview Schedule Adult Version, Client Interview Schedule (ADIS-IV)

The ADIS-IV (Brown, DiNardo, \& Barlow, 1994) is a semi-structured diagnostic interview designed for the assessment of current DSM-IV anxiety, mood, somatoform and substance use disorders in adults. It is designed to provide information sufficient for differential diagnosis among the anxiety disorders along with the creation of a functional analysis. Additionally, the ADIS-IV contains screening questions for psychotic symptoms along with information related to family psychiatric history. The ADIS-IV has previously shown good interrater diagnostic reliability (Brown, DiNardo, Lehman, \& Campbell, 2001).

\section{$\underline{\text { Yale-Brown Obsessive-Compulsive Scale (Y-BOCS) }}$}

The Y-BOCS (Goodman, Price, Rasmussen, Mazure, Fleischmann et al., 1989) is a 10item measure of obsession and compulsion severity over the past month. OCD patients or their family members are asked to provide a symptom rating on a scale of 0 to 4 , with a total score derived out of 40 comprised of two subscale scores for obsessions and compulsions. Higher scores equal greater OCD symptom severity. The Y-BOCS has shown good reliability and validity (Woody, Steketee, \& Chambless, 1995) and is considered the gold-standard of OCD symptom assessment.

\section{University of Rhode Island Change Assessment (URICA)}

The URICA (McConnaughy, Prochaska, \& Velicer, 1983) is a 32-item self-report measure assessing readiness to change, with four 8-item subscales representing the constructs of precontemplation, contemplation, action, and maintenance. The URICA has previously shown good reliability and construct validity and has a history of being adapted for use with anxiety disorder populations (Dozois, Westra, Collins, Fung, \& Garry, 2004). 
Treating a Mother's Accommodation Behaviors of Her Adult Son's OCD:

The Case of "Brianne" and "Charlie"

J. Marinchak

Pragmatic Case Studies in Psychotherapy, http://pcsp.libraries.rutgers.edu

Volume 9, Module 1, Article 1, pp. 1-57, 02-17-13 [copyright by author]

\section{Assessment Measures to Assess Brianne's Mental Health Status and Family Accommodation Behaviors}

Anxiety Disorders Interview Schedule Adult Version, Client Interview Schedule (ADIS-IV; see above)

Depression Anxiety Stress Scale - 21 (DASS-21)

The DASS-21 (Lovibond \& Lovibond, 1995) is a self-report measure which asks participants to rate their experiences of depression, anxiety and stress over the past week using a 0-3 scale. The DASS-21 yields three 7-item subscales between 0-21 and a total score range between 0-63. For both the subscales and the total score, higher scores reflect a greater degree of negative state emotion. The range of the normal population on the total score is between 0 and 30. The DASS-21 has shown adequate reliability and is a well-validated self-report measure of depression, anxiety, and stress (Brown, Chorpita, Korotitsch, \& Barlow, 1997).

\section{World Health Organization-Quality of Life-BREF (WHOQOL-BREF)}

The WHOQOL-BREF (Skevington, Lotfy, \& O’Connell, 2004) is 26-item self-report assessment measure of quality of life and is comprised of four specific domains: Physical Health, Psychological Health, Social Relationships, and Environmental Stress. The WHOQOL-BREF is a truncated version of a larger quality of life inventory and has shown excellent reliability and good validity. Additionally, the measure has shown strong cross-cultural validity and is useful for ascertaining the various meanings different cultures hold in regard to their lives and potential problems they may experience in them.

Family Accommodation Scale for Obsessive-Compulsive Disorder: Interviewer-Rated (FAS-IR)

The FAS (Calvocoressi, Mazure, Kasl, Skolnick, Fisk, et al., 1999) has been shown to have excellent reliability and good validity (Calvocoressi et al., 1999), and has been commonly utilized in family accommodation studies of treatment-seeking OCD individuals. The FAS consists of two sections: (1) a list of items asking relatives to identify current OCD symptoms based on a Y-BOCS derived checklist, and (2) a list of 12 items designed to provide a quantifiable measure of the frequency and severity of accommodation behaviors. The items in section 2 are rated from 0 to 4, yielding a range of 0-48. The full FAS measure is presented in Appendix 1.

Table 1 presents the results and clinical meaning for Brianne at pre and post assessment time points on the DASS-21, the WHOQOL-BREF, and section 2 of the FAS-IR.

\section{THE CLIENT}

"Brianne" is a Caucasian woman in her 40s. At the time of her entry into treatment, she had been married to her husband "Jack" for over twenty years and together they had two adult children," Shane," 22, and "Charlie," 18. Both children still lived at home with Brianne and her husband, and she split her time between managing the household and working part-time. Brianne 
Treating a Mother's Accommodation Behaviors of Her Adult Son's OCD:

The Case of "Brianne" and "Charlie"

J. Marinchak

Pragmatic Case Studies in Psychotherapy, http://pcsp.libraries.rutgers.edu

Volume 9, Module 1, Article 1, pp. 1-57, 02-17-13 [copyright by author]

was a high-school graduate and had earned post-high school diploma from a professional career development institute. She reported no history of medical or mental health issues and had never before personally received psychotherapy, taken psychiatric medications or been hospitalized.

Brianne was initially referred to the study through her attendance along with Charlie at an OCD support group held at the clinic where the treatment took place. While Charlie had a diagnosis of OCD, he refused any treatment. Neither Jack or Shane had any mental health issues.

\section{GUIDING CONCEPTION WITH RESEARCH AND CLINICAL EXPERIENCE SUPPORT}

\section{"Family Accommodation" and OCD}

Family members frequently become influential in the expression of OCD symptomatology, indicating one possible reason OCD has such a powerful negative impact on the family unit. Researchers have developed the term "family accommodation" (Calvocoressi et al., 1995, 1999) to define the process whereby family members of a patient either subtlety or overtly assist or participate in their family member's rituals (Cooper, 1996; Steketee \& Van Noppen, 2003). Examples of active accommodation behaviors can include providing reassuring statements to a family member with OCD or directly participating in their rituals, such as cleaning supposedly contaminated objects upon request. Additionally, many family members may passively or inadvertently accommodate OCD by changing family customs or routines, taking over responsibilities, and in the case of children minimizing disciplinary actions in response to normal behavioral transgressions (Storch et al., 2010). All of these actions reinforce the performance of rituals by reducing the associated emotional and practical consequences for the patient choosing to ritualize.

Family accommodation of OCD appears to be exceedingly common among family members of both child and adult OCD patients, with studies routinely showing accommodation rates of more than 60\% among first-degree relatives (Renshaw, Steketee, \& Chambless, 2005; Shafran \& Ralph, 1995; Storch et al., 2007). There are a variety of reasons why someone chooses to accommodate their loved one's rituals. Accommodation behaviors have been shown to be related to increased levels of family dysfunction and stress, emotional over-involvement with the identified patient (Van Noppen \& Steketee, 2009) and a lack of educational information regarding the nature of the disorder itself. In some cases, family members may elect to accommodate rituals simply as a means of minimizing household disruption. Additionally, according to a study on accommodation by Calvocoressi and colleagues (1995), approximately $40 \%$ of OCD-family respondents reported a feeling of responsibility towards their family member's OCD. These numbers are consistent with those found in other surveys of OCD families (Shafran \& Ralph, 1995), and suggest that feelings of guilt towards a family member's OCD may drive family members to devote their energies towards removing obsession-triggered anxiety.

These numbers are especially disturbing when the psychological ramifications of ritual accommodation are considered for both parties. According to behavioral theoretical models of 
Treating a Mother's Accommodation Behaviors of Her Adult Son's OCD:

Pragmatic Case Studies in Psychotherapy, http://pcsp.libraries.rutgers.edu

Volume 9, Module 1, Article 1, pp. 1-57, 02-17-13 [copyright by author]

OCD, engaging in ritualistic behavior in response to obsessions provides negative reinforcement through the reduction of anxiety and an increased sense of safety from the obsessional trigger (Franklin \& Foa, 2008). Therefore, family members accommodating their loved one's rituals are in actuality harming them by strengthening their anxiety-response and increasing their reliance on their rituals. This negative effect is borne out in the literature, as family accommodation has been associated with more severe OCD symptomatology (Steketee \& Van Noppen, 2003; Storch et al., 2010) and poorer outcomes after behavioral OCD treatment (Amir, Freshman, and Foa, 2000; Chambless \& Steketee, 1999; Storch et al., 2008;). Thus, families attempting to help their loved one cope with distress engendered by their OCD symptoms are inadvertently making it more difficult to fight back against the disorder.

The negative psychological cfonsequences of accommodating OCD extend beyond the identified patient to impact non-OCD family members as well. Family accommodation is significantly associated with elevated levels of distress among family members and poorer overall family functioning (Albert et al., 2010; Steketee \& Van Noppen, 2003). It has also been shown to be highly correlated with increased severity of OCD symptoms (Storch et al., 2010). Thus, it is likely that family members who accommodate find themselves devoting increasing amounts of time and energy to accommodating OCD as their loved one's symptom severity increases. One recent study administered quality-of-life health questionnaires to first-degree relatives of OCD patients and found caregivers of OCD patients and in particular accommodating caregivers were at an elevated risk to experience personal mental distress (Albert, Salvi, Saracco, Bogetto, \& Maina, 2007).

Several current evidenced-based psychological treatments for OCD in both children and adults incorporate family members into treatment in response to these findings (For review, see Renshaw, Steketee, \& Chambless, 2005). The majority of these treatments provide the family with psycho-education on the nature of OCD and the negative impact that rituals, and more specifically, accommodation of rituals have on symptom expression. Family members are frequently taught non-accommodating coping strategies that can be utilized in multiple environments outside the therapy office. Some examples include responding to OCD-related questions in a non-reassuring manner, removing ritual-facilitating items from the home and providing encouragement and support to their loved one when they attempt to resist their rituals. OCD therapists may also need to spend several sessions working with the family unit to alter unhealthy communication styles, as family responses characterized by hostility and/or overinvolved emotionality towards the OCD patient can negatively impact behavioral treatment outcome (Chambless \& Steketee, 1999; Steketee, 1993). OCD therapists typically advocate an approach whereby family members adopt a communication style towards their loved ones of "non-hostile criticism." This style is characterized by direct, concise verbalized criticism and dissatisfaction towards the OCD-family member for their decision to ritualize (e.g. "I know it's not an easy thing to do, but I wish you would try harder to fight back against your OCD”) rather than an outright rejection of the whole person (e.g. "I can't stand being around you when you're like this!”). Several authors suggest that relying on non-hostile criticism implicitly communicates the belief that their loved one has the ability to cope with and overcome their OCD (Chambless \& Steketee, 1999; Steketee \& Van Noppen, 2003). Such communications may increase patients' 
Treating a Mother's Accommodation Behaviors of Her Adult Son's OCD:

The Case of "Brianne" and "Charlie"

J. Marinchak

Pragmatic Case Studies in Psychotherapy, http://pcsp.libraries.rutgers.edu

Volume 9, Module 1, Article 1, pp. 1-57, 02-17-13 [copyright by author]

feelings of self-efficacy towards fighting their OCD and result in increased motivation to seek therapeutic help.

Many OCD therapists now routinely recommend family involvement in OCD treatments for both children and adults. Family-oriented treatments reduce OCD-related distress and quality-of-life in both patients and their family members and have the potential to improve relationship quality between family members (Renshaw, Steketee, \& Chambless, 2005). However, most of these family-oriented interventions have been studied and implemented with a population of treatment-seeking adult OCD individuals and their families, or with children where the adult caregiver typically makes the decision to enter the child into treatment. For adult individuals with OCD the level of motivation for treatment becomes more important, as therapists can typically only legally provide therapy to individuals over the age of eighteen who voluntarily elect to pursue treatment. Thus, some family members may desire that their loved one receive help for their OCD, with the family member being in a position to ultimately decline or accept a treatment option.

The implication of this potential conflict takes on added significance when considering the number of adults with OCD living in the same household with immediate family members (i.e. parents, spouses, siblings). There are estimates based on OCD family research that up to $25 \%$ of adults with OCD currently live with their parents (Steketee \& Pruyn, 1998). Although some studies find OCD adults are less likely to be married than individuals in the general population, others have found marriage rates for OCD adults to be similar to those in the general population (Koran, 2000). Taken all together, these numbers indicate that adults with OCD tend to have a family constellation characterized by close proximity to immediate family members, a finding which is not surprising when considering the significant distress engendered by OCD and the tendency for family members to take on added responsibilities in coping with a relative's mental illness (Fadden, Kuipers, \& Bebbington, 1987).

\section{The Substantial Number of OCD Adults Who Do Not Receive Treatment}

It is also well-known that despite the presence of effective psychological and pharmacological OCD treatments (Franklin \& Foa, 2008), a significant percentage of OCD adults do not receive any form of treatment. In a review of treatment utilization among Australian individuals with anxiety disorders, researchers found only $11 \%$ of individuals had received an appropriate evidenced-based treatment for their condition (Issakidis \& Andrews, 2002) This number is consistent with other findings showing $40 \%$ of individuals with OCD do not receive needed care when taking into account treatment non-responders, drop outs, and those who outright refuse treatment (Jenike, 2004). In the Australian sample (Issakidis \& Andrews, 2002), non-treatment seekers provided a variety of reasons why they chose to not seek out help from mental health professionals, with a majority (58\%) asserting a desire to manage their condition on their own. Another potential reason OCD patients in particular may not seek help is that the current gold-standard psychological treatment for OCD, exposure and response prevention (EX/RP), requires patients to devote considerable time and effort and willingly experience high levels of emotional distress for extended periods of time (Maltby \& Tolin, 2003). OCD patients may also have experienced limited success during past treatment episodes 
Treating a Mother's Accommodation Behaviors of Her Adult Son's OCD:

Pragmatic Case Studies in Psychotherapy, http://pcsp.libraries.rutgers.edu

Volume 9, Module 1, Article 1, pp. 1-57, 02-17-13 [copyright by author]

and now feel hopeless over the possibility of receiving any future potential benefit from therapy. Due to the large number of treatment-refusing OCD patients, researchers have recently begun efforts to incorporate motivational enhancement techniques prior to the onset of exposure techniques as a way to enhance treatment compliance and reduce dropout rates (Maltby \& Tolin, 2005; Riccardi, Timpano, \& Schmidt, 2010; Simpson \& Zuckoff, 2011). However, the results of these efforts so far have been mixed.

\section{Family Accommodation Can Reduce the OCD Adult's Motivation for Treatment}

In addition to an OCD patient's personal negative beliefs regarding treatment, the results of family accommodation research suggest that the behaviors and attitudes family members take towards OCD may influence treatment motivation. Accommodating behaviors may decrease an individual's sense of self-efficacy to tackle their OCD symptoms (Steketee \& Van Noppen, 2003). Additionally, accommodation reduces the personal cost to the patient of living with OCD by continually removing anxiety and adjusting the family's activities to correspond to OCD. Thus, accommodation behaviors make it easier for a person already low in motivation to continue living their lives in a manner adjusted to their OCD at a reduced cost.

\section{Developing a CBT Treatment to Reduce Family Accommodation}

Based on the current understanding of the negative impact of family accommodation and the high numbers of adult OCD patients who do not seek appropriate treatment for their condition, I developed a 10-session, family-member-oriented psychological intervention provided individually to a primary family member living with an adult OCD sufferer currently unmotivated to seek treatment. The intervention uses evidenced-based techniques grounded in existing family-oriented OCD treatments to target specific accommodation behaviors, attitudes, and communication styles in the non-OCD family member that are deemed to be either ineffectual or detrimental. The specific treatment interventions are drawn from existing manualized OCD-family interventions (e.g. March \& Mulle, 1998) as well as existing cognitive behavioral treatment theory, case formulation, and practice techniques (Persons, 2008), which include elements such as communication training, behavioral analysis, cognitive restructuring, and exposure techniques. The use of specific CBT modules or intervention strategies is determined through an individualized case conceptualization (Persons, 2008), derived from the results of the pre-intervention interview and baseline measures. Additionally, a small battery of self-report forms is administered every two weeks at the onset of treatment sessions.

Treatment with the primary family member is designed to be conducted individually with the therapist at the anxiety clinic free of cost. Treatment is designed to occur in weekly, 50minute sessions over the course of ten weeks. During the treatment phase, the therapist has no direct contact with the OCD relative unless specifically requested by that individual. If such contact should occur, no information regarding the non-OCD family member's treatment is discussed. The family member receiving treatment continues to have contact with his or her OCD relative as normal and is frequently encouraged to speak to the relative regarding OCDrelated family issues as part of the treatment assignments. 
At treatment termination, the family is notified that the OCD family member is eligible to receive free treatment at the anxiety clinic at any point in the future through their participation in the study. If either the primary family member or the OCD family member requests additional treatment services at the completion of treatment, a referral would be provided by the principal investigator.

An outline of the treatment manual is presented in Table 2.

\section{The Present Case}

I was the therapist and the above research protocol and treatment program were employed in the case of Brianne and Charlie with the goal providing benefits to all of Brianne's family members. Specifically, the treatment was designed to improve family OCD-related communication, which was expected (a) to reduce symptoms of depression, anxiety, and general stress in the non-OCD family members (Brianne, Jack, and Shane) and thus to improve their general quality of life; and (b) to reduce Charlie's symptom severity and augment his level of motivation to seek future treatment.

\section{ASSESSMENT OF THE CLIENT'S PROBLEMS, GOALS, STRENGTHS, AND HISTORY}

\section{Client Background and Entry into Treatment}

Brianne is a Caucasian woman in her 40s. At the time of her entry into the treatment study, she had been married to her husband Jack for over twenty years and together they had two adult children, Shane, 21 and Charlie, 18. Both children still lived at home with Brianne and her husband and she split her time between managing the household and working part-time. Brianne was a high-school graduate and had earned post-high school diploma from a professional career development institute. She reported no history of medical or mental health issues and had never before personally received psychotherapy, taken psychiatric medications or been hospitalized.

Brianne was initially referred to the study through her attendance along with her son Charlie at the OCD Support Group held at the anxiety clinic where the therapy took place. Brianne had been referred to the group after speaking over the phone with a current group member, who in her spare time provides outreach services for family members of individuals diagnosed with OCD. Brianne had indicated that she was seeking more information on OCD and treatment options for her son, who at that time did not wish to receive treatment on his own. The current group member recommended the support group due to its open nature for both individuals with OCD and their family members and its emphasis on providing support rather than treatment.

At the group, Brianne spoke openly about her frustrations dealing with her son Charlie's OCD behaviors in the house and her difficulties extricating herself from his rituals and his constant requests for physical comfort and verbal reassurance. Brianne indicated that her son Charlie was no longer interested in receiving treatment for his OCD and had begrudgingly 
Treating a Mother's Accommodation Behaviors of Her Adult Son's OCD:

Pragmatic Case Studies in Psychotherapy, http://pcsp.libraries.rutgers.edu

Volume 9, Module 1, Article 1, pp. 1-57, 02-17-13 [copyright by author]

agreed to attend the current support group only after she had made several requests. Based on her description, the OCD group leader, a fellow graduate student familiar with the current study, briefly described the research project to Brianne and inquired whether she would be interested in receiving more information from the principal investigator/therapist. Brianne expressed interest and voluntarily agreed to provide the principal investigator with her contact information in order to speak further about the study over the phone.

In my roles as the principal investigator and potential therapist, I contacted Brianne the following day. I described in detail the nature and procedures of the current study along and provided a brief rationale why she would be receiving treatment rather than her son if they were to enter into the study. She was also informed of the study's procedures to protect confidentiality and made aware of the study's inclusion/exclusion criteria. She verbally indicated that she fully understood the information, including the desire to help family members decrease accommodation and learn new behavioral strategies in response to their loved ones OCD. Furthermore, she stated that she had recently been trying on her own to disengage from her son's rituals and would therefore be highly motivated to receive professional help in this endeavor.

At my request, Brianne stated that she would go over the study information with her son and inform him that he could contact the investigator if he had any questions or hesitations about entering into the study. The following day, Brianne contacted and informed me that both she and her son Charlie were willing to participate. An appointment was scheduled with me the following week for the in-home, pre-treatment consent signing and assessment.

\section{Assessment Procedures}

Prior to the beginning of treatment, I conducted an initial assessment with both Brianne and Charlie. The purpose of the pre-treatment assessment was threefold: 1) to determine study eligibility; 2) if eligible, to obtain baseline scores of mental health functioning and treatment motivation for Brianne and Charlie; and 3) to develop an accurate, comprehensive understanding of the accommodative relationship between Brianne's behaviors and Charlie's OCD, with a particular focus on identifying potential environmental and family systems factors. Along with the standardized quantitative measures (see results below), I initially utilized an unstructured clinical interview with both Brianne and Charlie in order to ascertain more detailed information on the history of Charlie's OCD and its current impact on Brianne's overall functioning and mental health.

The questions for this interview were derived from the four-factor method of assessment and intervention (Petronko, Harris, \& Kormann, 1994). This approach was initially designed for community-based interventions with dually-diagnosed individuals (i.e. individuals with some form of intellectual disabilities and one other disorder). This method is designed to provide the assessor with an accurate functional analysis of behavioral interactions at multiple levels, including individual, caregiver, environment and overall system. This information is then incorporated into the overall case conceptualization and utilized in the planning of treatment, which is often targeted towards primary caregivers when working with a dually-diagnosed population. Through the use of multi-level functional analyses, the four-factor model strives to 
Treating a Mother's Accommodation Behaviors of Her Adult Son's OCD:

Pragmatic Case Studies in Psychotherapy, http://pcsp.libraries.rutgers.edu

Volume 9, Module 1, Article 1, pp. 1-57, 02-17-13 [copyright by author]

increase the likelihood of behavioral change not only through accurate behavioral interventions but also through increasing the likelihood that therapeutic interventions will continued to be implanted by the caregiver once treatment has ended.

The goals of the four-factor model of behavioral assessment were deemed to coincide with the stated aims of the current study, specifically to target a behavioral intervention to the loved one/caregiver of an individual with OCD. Furthermore, the highly individualized nature of four-factor assessment coincides with the pragmatic case study research model, particularly through the ability to generate detailed data on accommodation behaviors and mental health functioning across various contexts and systemic levels.

\section{Clinical History}

Prior to the development of his OCD, Charlie as a child had been diagnosed with an auditory processing disorder and mild mental retardation. Despite these diagnoses, Brianne reported that Charlie as a child had functioned normally both at home and at school with the help of an individualized education program (IEP). Although Brianne recalled Charlie displaying some mild avoidance behaviors as a child, she did not recall him displaying any pathological anxiety or distress.

Charlie’s OCD behaviors began three years ago immediately following his being informed that his brother had been involved in a traumatic accident involving a lawn mower while Charlie and his mother were not home. Brianne's oldest son, Shane, had been mowing the front lawn when he accidently caught his foot in the mower and severed four toes. Brianne and Charlie had been out driving together when she received a phone call describing what had happened and informing her that her son was being taken to the local emergency room. As they were driving to the hospital, Brianne reported that her cell phone battery died and they became stuck in traffic. She described the time it took to arrive at the hospital as being extremely frightening for both herself and Charlie, due to their inability to receive information about Shane. When they arrived at the hospital, Charlie happened to view his brother's injured foot which Brianne reported caused him to become extremely upset.

Soon after this traumatic incident, Charlie began to experience significant daily anxiety and started avoiding particular areas of the house he associated with his brother's accident, particularly a window in their living room looking out on the front lawn. He would frequently worry about his brother's health throughout the day and became phobic of hospitals. While Brianne viewed these avoidances as stemming from Charlie's reaction to the family trauma, she also began noticing that Charlie was in engaging in other odd behaviors which she had never seen before. Charlie gradually became insistent that items in his room, often times clothes, needed to be left in specific areas. If Brianne or other family members attempted to remove or move items, Charlie would become extremely upset and demand they be placed back in their original position.

Also, Brianne observed Charlie engaging in repetitive behaviors such as repeatedly turning light switches on and off and walking up and down a staircase multiple times. As time 
Treating a Mother's Accommodation Behaviors of Her Adult Son's OCD:

The Case of "Brianne" and "Charlie"

J. Marinchak

Pragmatic Case Studies in Psychotherapy, http://pcsp.libraries.rutgers.edu

Volume 9, Module 1, Article 1, pp. 1-57, 02-17-13 [copyright by author]

went by, Charlie began expressing a strong preference for odd numbers and an avoidance of any even numbers. Later, he began incorporating this preference for odd numbers into his repeating rituals, for example turning a light switch on/off only an odd number of times. More recently, Charlie had started engaging in more complex repeating activities, such as feeling the need to return to a location he had recently moved from in order to leave again. This particular compulsion had been happening with such frequency that the family developed the term "backstepping" to describe the activity. When family members would ask Charlie why he felt the need to perform these actions, he was unable to verbally articulate any reasons or thoughts that were preceding his behaviors. Instead, he would simply insist to family members that they made him feel better, which they took to mean made him less anxious.

After the trauma, Charlie began experiencing significant anxiety when separated from his mother and became reliant on her for reassurance when he was feeling anxious. He would repeatedly ask his mother to tell him she loved him throughout the day and would become extremely upset if Brianne would leave him alone in the house. He began to request physical contact from Brianne, for example asking her to hug him multiple times a day, sometimes even when they were in the middle of a conversation. If Brianne refused his request, Charlie would try to engage in alternative means of contact, such as holding her hand or putting his foot on top of hers. Charlie would also call Brianne multiple times a day, even when she was at work, usually without any purpose other than just to check in. As Charlie's dependence on Brianne expanded, he began to socialize less and less with peers in school. He frequently would come home immediately after school in order to wait for Brianne to return from work, participated in very few extra-curricular activities, and had very few close relationships outside of his immediate family. Charlie also refused many developmental milestones common for other students his age, such as learning to drive a car and getting a part-time job. Brianne and her husband believed Charlie was physically and mentally capable of performing these activities, but they worried he would be unable to handle them emotionally due to his anxiety and compulsions.

Charlie's avoidance and repeating behaviors around the house grew to such severity that Brianne sought in-home behavioral therapy in 2009 when he was sixteen. Although Charlie initially resisted entering into therapy, he reluctantly agreed when his mother informed him the therapist would come to their home and he wouldn't have to venture outside the home for appointments. The therapist worked with Charlie on gradual exposure exercises of avoided areas of the house, such as the front window and certain areas of his room. Charlie reluctantly participated in his exposures and began to experience moderate reductions in his anxiety and avoidance. At that time, Charlie received diagnoses of post-traumatic stress disorder stemming from his brother's accident in addition to obsessive-compulsive disorder. The therapist explained the nature of OCD to Brianne and briefly highlighted ways in which the family was participating in Charlie's rituals and making it easier for him to avoid consequences of his behavioral choices. At the conclusion of the treatment, Charlie experienced significantly less anxiety related to his brother's trauma, although his phobia of hospitals remained. Although his repeating compulsions also decreased, he quickly became lax about practicing his exposure exercises once therapy terminated and his therapist was no longer present to motivate him. In the two years since that treatment's termination, Brianne reported Charlie's symptoms had returned to their pre-treatment baseline levels. 
Treating a Mother's Accommodation Behaviors of Her Adult Son's OCD:

The Case of "Brianne" and "Charlie"

J. Marinchak

Pragmatic Case Studies in Psychotherapy, http://pcsp.libraries.rutgers.edu

Volume 9, Module 1, Article 1, pp. 1-57, 02-17-13 [copyright by author]

\section{Four-Factor Assessment of Current Quality of Life}

\section{$\underline{\text { Individual Level }}$}

At the time of the pre-treatment assessment, Brianne reported that Charlie spent most of his daytime hours working as a teacher's aide at a local elementary school. He relied on Brianne to take him to work every morning, and because he often had difficulty leaving the house without ritualizing. Several of Charlie's rituals focused on repetition of proscribed behaviors, such as turning light switches in the house on and off a specific number of times, with the number always having to be even. Additionally, Charlie would frequently retrace his steps during the day, stating that he needed to return to a location he had just come from and take the same route back. When his retracing behaviors required traveling a significant distance, he would often request Brianne or his father drive him back where he had just come from. His requests for travel assistance had become so frequent that his family nicknamed this ritual "backstepping.”

Charlie also displayed concerns regarding symmetry and order of his personal possessions, forbidding other family members from touching or moving items in his room that he had placed in specific locations. Finally, Charlie would frequently ask Brianne for verbal and physical reassurance, repeatedly asking her whether she still "loved him" and requesting that she hug him throughout the day, especially when he was feeling anxious or upset. Importantly, the majority of Charlie's rituals took place around the family home, particularly when Brianne was nearby and capable of giving attention to Charlie.

Due to the extent of Charlie's rituals, Brianne would often be late for her work appointments. After school, Charlie would typically return home and await Brianne's return from work. Immediately upon her arrival, he would proceed to shadow her movements around the house and make repeated attempts to have physical contact. This type of shadowing behavior would continue throughout the night, and if Brianne ever needed to leave the house he would insist on accompanying her. If Brianne tried to create some separation for herself from Charlie, for example closing the bedroom door in order to speak privately with her husband, Charlie would behave in ways designed to bring his mother's attention back onto him, such as repeatedly knocking on the bedroom door or walking loudly back and forth in the hallway and up the stairs. Although Charlie and his brother Shane shared a videogame system located in his brother's room, Charlie had recently been banned from use by Brianne because the family suspected Charlie of taking important papers from his brother's desk and ripping them apart, in an apparent effort to self-soothe. Charlie's behaviors caused a great deal of conflict between himself and his brother, which Shane typically dealt with by complaining to Brianne rather than speaking directly to Charlie. Brianne would typically respond by forbidding Charlie from entering into his brother's room or touching his brother's possessions. While this strategy was somewhat helpful in preventing Charlie from destroying his brother's property, it served to create a distance between Charlie and Shane and reinforced Shane's behavior of turning to Brianne for help when upset about Charlie's OCD behavior rather than speaking to his brother directly about his OCD behaviors. 
Treating a Mother's Accommodation Behaviors of Her Adult Son's OCD:

Because many of Charlie's rituals and routines were being accommodated by his mother and other family members (see caregiver section), he experienced very minimal real-life consequences for his behaviors. The teacher for whom Charlie worked had contacted Brianne in the past to complain about Charlie's morning tardiness, but rarely did Charlie directly experience any reprimands from his parents or the school. When Charlie would complain that he was unable to pick-up an item from his room because it was located in an area which caused him anxiety, one of his parents would often help him by picking up the item and bringing it to him. Additionally, family members would frequently re-arrange normal family routines, such as the laundry schedule, because Charlie had not done his wash on his specified day or had accrued a large number of towels to be washed due to his repetitive rituals involving drying himself. Finally, Brianne and her husband reported that they would frequently assist Charlie in his "backstepping” rituals, often by physically driving him to a previous location. Brianne insisted both she and her husband didn't want to help him “back-step” but felt it would reduce his anxiety in the long-run and prevent him from having difficulty functioning over the next few days due to an acute anxiety spike.

One primary consequence of Charlie’s shadowing behavior was that Charlie had very little incentive to interact socially with peers. At the initial assessment, Charlie would occasionally mention his desire to obtain a part-time job after his school aid position ended in the summer and pursue getting a girlfriend. However, Brianne stated that Charlie had not taken any steps towards achieving these goals despite her frequent encouragement, and she worried that his difficulty being apart from her would prevent him from pursuing these developmental milestones. Brianne felt extremely frustrated with Charlie around the house, particularly during times when he refused to give her space to herself. Frequently, Brianne would raise her voice to Charlie or tell him how he was "driving her crazy". At some point after these incidents, Charlie would return to his mother and ask her if she still loved him, with his mother always responding in the affirmative.

\section{Caregiver (Mother) Level}

As the primary caregiver for Charlie and the rest of the family, Brianne had become the primary facilitator of Charlie's OCD rituals. Since the lawnmower accident in 2007, she devoted her time and energy to her son and became more and more anxious whenever she was not around him. Brianne explained that she found it difficult not to think of Charlie if she was away from him, in part because she worried what rituals he might be performing around the house. She was aware Charlie had become increasingly isolated from his peers, and she worried Charlie would eventually become totally socially dependent on his family and unable to work or function without his family's care and accommodation.

As a result of her accommodation and anxiety, Brianne's quality of life began to suffer. She rarely had time to herself around the house, and stated that it was impossible for her to feel relaxed at home due to Charlie's constant presence and need for attention. She reported that her work life had been affected by Charlie's OCD, as she was unable to find time in the evenings to create lesson plans and at one time had to pass on a promotion to work more hours because it 
Treating a Mother's Accommodation Behaviors of Her Adult Son's OCD:

Pragmatic Case Studies in Psychotherapy, http://pcsp.libraries.rutgers.edu

Volume 9, Module 1, Article 1, pp. 1-57, 02-17-13 [copyright by author]

would mean Charlie would be by himself at home. Also, Brianne would frequently be late for work in the mornings due to waiting for Charlie to finish his rituals before driving him to school.

Increasingly, she had been spending less and less time with her husband and older son as Charlie had taken over her time and attention. She and her husband rarely had time to themselves around the house, something Brianne mentioned she craved after a long day at work. They had not been out for a romantic evening together in the last year because they were concerned Charlie would become anxious and could not handle his parents being away from the house. Brianne had also sacrificed spending time with her older son, Shane, and stated that she felt disconnected from him and worried that he resented the energy and attention she gave to Charlie and his OCD.

In response to Charlie's OCD and attention-seeking behaviors, Brianne frequently experienced significant feelings of frustration, anger and resentment. She felt as if she "never got any peace" or time to herself and would often get angry and threaten to remove his privileges as punishment when he was attempting to get her attention. Brianne confided that these feelings had become so powerful that at one time she had fantasized about "kidnapping" one of Charlie's stuffed animals and holding it hostage until he decreased a certain ritual. She never went through with this action and felt ashamed afterwards.

At the time of the initial assessment, Brianne reported that her quality of life was extremely poor due to her inability to disengage from Charlie's OCD and anxiety. She had recently begun seeking out educational information on OCD treatment and was frequently encouraging Charlie to re-enter therapy for his OCD. Although she hadn't previously considered entering into treatment herself, Brianne was able to recognize her own role in accommodating Charlie's OCD and she was extremely motivated to learn new ways of reacting to Charlie's rituals and improving her own quality of life.

\section{Environments (Home \& School)}

The primary environments for the expression of Charlie's OCD behaviors and Brianne's subsequent accommodation were their single-family home and Charlie's school. The majority of Charlie's rituals occurred in his house, and there were several areas of the home Charlie avoided, including parts of his bedroom and the backyard. At school, Charlie rarely engaged in OCD rituals, however school officials had become tolerant of his ritual-related morning tardiness and had never implemented a system of consequences.

\section{Family System}

In response to Charlie's OCD and separation anxiety, the family had adopted various roles that served to avoid confrontation with Charlie regarding his behaviors and implicitly reinforce the expression of his rituals. Both Charlie's father and brother would frequently disengage and avoid Charlie around the house, particularly at night when he was shadowing Brianne and engaging in rituals. Charlie's father often had to be up early for work and would frequently go to sleep very early in the evening, despite Brianne asking him to stay up later and help her set boundaries for Charlie. Brianne's oldest son, Shane, mirrored his father's withdrawal 
and spent a majority of his time outside of the house either in school, at work or with his girlfriend. The family frequently relied on Brianne to negotiate or smooth over household conflicts engendered by Charlie's rituals, rather than discussing their frustrations or concerns directly with Charlie. Frequently, Brianne would respond to complaints from Shane and her husband by taking over some of their household responsibilities that had become impacted by Charlie's rituals. For instance, Charlie's repeating rituals around doing laundry frequently disrupted the family schedule such that Shane and his father weren't able to do their laundry on their prescribed days. Instead of speaking with Charlie, Brianne would often do her husband and son's laundry for them at a different time in order to help keep the family peace. In this way, Brianne served as both the primary caregiver and negotiator for the family unit, striving to prevent OCD-related fissures from developing and disturbing the equilibrium of the household.

As a result of the care and attention Brianne displayed for Charlie, she suspected that her son Shane had grown upset by the amount of attention Charlie received from his mother and felt frustrated and angry with his brother, particularly when Charlie failed to maintain appropriate boundaries or follow rules inside the home, as with the videogame system. Shane's typical reaction to such events was not to speak with him directly but rather to go through his mother as an intermediary, resulting in Brianne feeling more stressed and caught in the middle of family conflict engendered by Charlie’s OCD.

\section{Quantitative Assessment}

\section{$\underline{\text { Charlie }}$}

As mentioned above in the Case Context section, the plan was to measure Charlie's mental health status at both pre-assessment and post-assessment using three standardized procedures that measure anxiety (ADIS-IV), OCD symptoms (Y-BOCS), and motivation for treatment (URICA). However, at pre-assessment it became clear that due to his developmental issues Charlie was unable to fully comprehend the language of these measures when presented both visually and verbally. It was decided that Charlie's scores on self-report and intervieweradministered study measures were unreliable and thus could not be accurately recorded. Instead, Charlie's OCD diagnosis and pre-treatment levels of OCD symptom severity and treatment motivation were derived from qualitative interviews with Charlie and Brianne.

\section{Brianne}

At the pre-treatment assessment, Brianne did not meet criteria for any current or past Axis-I disorder on the ADIS-IV clinical interview. The quantitative questionnaire scores for Brianne are presented in Table 1. As shown, Brianne's total pre-treatment score on the DASS-21 was a 7, falling within the normal range. (Her three clinical subscales-depression, anxiety, and stress - were also all within the normal range.)

On the WHOQOL-BREF, Brianne's quality of life pre-treatment standardized scores were $81^{\text {st }}$ percentile for Physical Health, $81^{\text {st }}$ percentile for Psychological Health, $69^{\text {th }}$ percentile for Social Relationships, and $69^{\text {th }}$ percentile for environmental stress: all in the normal range. 
Finally, on the "Family Member's Report of Accommodating Behaviors" section of the FAS-IR scale (see Appendix 1, p. 51-56 below), Brianne’s pre-treatment total score was 26, above the mean in degree of family accommodation within the 36 adult obsessive-compulsive patients and their primary caregivers on whom the measure was developed. Brianne's highest levels of accommodation fell into four domains, specifically, item 3, waiting on Charlie to complete his rituals; item 7, facilitating Charlie's avoidance behaviors; item 9, assisting Charlie in completing simple tasks around the home, and item 10, taking on Charlie's responsibilities around the home.

\section{FORMULATION AND TREATMENT PLAN}

\section{Case Formulation}

From information gathered during the pre-treatment interview, it was concluded that Brianne's accommodation behaviors of Charlie's OCD had both been present for a long period of time and were causing significant distress for Brianne, Charlie and their family. The preinterview assessment information was analyzed and framed by the four-factor theoretical model. On the individual level, Charlie's ability to continuously rely on his mother for attention and assistance was preventing him from socializing with peers and achieving important developmental milestones, such as getting a job. Furthermore, Charlie's lack of motivation to enter into OCD treatment appeared in many ways to be associated with the assistance he received from Brianne and the lack of consequences and boundaries in his environments.

From the caregiver perspective, Brianne was displaying many of the classic examples of family OCD accommodation, including providing reassurance, altering family routines, taking over responsibilities and in some cases directly participating in Charlie's ritual performance. Similar to other family members, Brianne frequently experienced feelings of anger in reaction to Charlie, and on occasion these feelings had led her to react with hostility, for example by yelling at him. Additionally, Brianne's anxiety and difficulty being away from Charlie indicated an emotional over-involvement with his OCD, whereby Brianne felt incapable of separating her own anxiety from Charlie's OCD. Finally, Brianne described a clear difficulty in practicing selfcare and allowing herself opportunities to separate from Charlie and have experiences outside of the sphere of OCD. Brianne believed there was no possibility for her to devote time for herself and her needs, and because of this, her relationships with her husband, son, family and friends were suffering.

From an environmental perspective, it appeared that in both of Charlie's primary day environments, namely at home and school, there were few consequences and boundaries put in place that might act as behavioral deterrents for his OCD and avoidance. For instance, his school did not feel able to reprimand Charlie for his morning tardiness, therefore there were no impediments for him to perform his rituals in the morning and rely on Brianne to take him late to school. At home, family members had become accustomed to assisting Charlie when his decisions to avoid certain stimuli made it difficult for him to function. Finally, it appeared that the larger family system had over time evolved in way to not only facilitate Charlie's OCD but also to acknowledge and accept Brianne's role as the key accommodator and safety object for 
Charlie. The father Jack and older son Shane's decisions to withdraw from Charlie's OCD reinforced Charlie's reliance on his mother and made Brianne feel even more trapped and alone.

\section{Treatment Plan}

In developing a short-term treatment plan, I deemed it important to address all four factors in order to both increase the efficacy of the initial intervention and the likelihood of Brianne implementing changes consistently over the long term. I anticipated that I would need to devote initial sessions to enhancing caregiver motivation for treatment and/or addressing concerns that treatment was not being directly provided to their loved one. However, for Brianne this was deemed unnecessary due to her extremely high level of motivation at the beginning of treatment and her strong desire to separate herself from her son's OCD. In keeping with a cognitive-behavioral orientation, the treatment plan was designed to utilize a short-term, problem-focused approach whereby Brianne and I would learn new ways of understanding and reacting to Charlie's OCD. The material learned during therapy would be reinforced through the administration of homework assignments designed to facilitate Brianne's practice and generalize treatment effects into the home environment. Finally, at the end of treatment I would summarize Brianne's, I would introduce relapse prevention techniques, and I would make a referral for additional treatment if necessary.

In addition to the individual-oriented goals of reducing accommodation and increasing OCD understanding, I decided to incorporate some interventions designed to address the larger family systems-level issues of Jack and Shane's withdrawal behaviors and Brianne's own feelings of resentment over not having time for personal self-care activities. Specifically, I determined that part of the treatment should focus on encouraging Brianne to devote free time to enjoyable activities outside the realm of Charlie's OCD that she had sacrificed in recent years in order to focus on Charlie. For example, Brianne complained that she hadn't gone out on a date with her husband Jack in well over a year due to Charlie's anxiety over not having her in the house. It was determined that a treatment goal of having Jack and Brianne spend an evening together would address the individual issue of Brianne's feelings of resentment and the familysystems level issue of Jack feeling distant and cut-off from his relationship with Brianne due to Charlie's OCD needs.

\section{COURSE OF THERAPY}

The following is a session-by-session description of the course of Brianne's treatment. In addition, Table 3 presents a subjective clinical rating by the therapist of Brianne's past-week total accommodation behaviors in which a score of ten denoted the highest possible level of accommodation behaviors, five moderate accommodating behaviors, and zero no presence of accommodation within the home.

\section{Session 1}

The first treatment session focused on re-assessing Brianne's motivation for treatment, elaborating Brianne's short term/long term goals, providing psycho-education information on the 
function of rituals in OCD, and assigning Brianne an initial behavioral homework assignment. Brianne reported that her motivation for treatment remained high and she had already attempted to set a limit with Charlie by asking him to give her some time to herself before going to bed. However, it had been difficult for her to maintain this boundary with Charlie due to his frequent attempts to gain her attention by engaging in distracting behaviors in her presence. Both Brianne and I examined the consequences of her reactions to Charlie's behaviors, which typically involved her giving Charlie attention by discussing her annoyance with his actions. I encouraged Brianne to maintain her evening-time boundary and I suggested some alternative strategies designed to limit her engagement with Charlie, such as ignoring him or relocating to her bedroom with the door closed.

I rated the past-week accommodation 5 out of 10 .

\section{Session 2}

At session two, Brianne reported that she had experienced success maintaining her evening-time boundary. As a result, she had used the time to herself to prepare for work the next day, something she had not been able to do in the past. Brianne believed that Charlie had been more anxious during the week as a result of not being around his mother in the evening. Perhaps due to his anxiety, Charlie had violated a family rule by eating his brother Shane's yogurt in the refrigerator after Charlie had already finished his own allotment. Brianne reported that she had been very upset at Charlie and had yelled at him, but had eventually gone to the store and bought more yogurt for Charlie and the rest of the family. A discussion followed regarding the importance of Charlie experiencing the natural environmental consequences of his rituals and rule-breaking behaviors.

I asked Brianne whether she thought having Shane speak directly to Charlie about his displeasure over Charlie eating his food, but Brianne stated she didn't believe Shane would want to do this. I explained to Brianne that her response to Charlie often prevented him from experiencing these consequences, such as when she bought him more yogurt or when she waited him to complete his rituals in the morning and drive him to school. Brianne stated that in the past school officials had spoken with her several times regarding their frustration that they were unable to discipline Charlie when he would arrive late to class or to his teaching aid position. It was pointed out to Brianne that if it were left to Charlie to get to school on his own and he continued his morning rituals, experiencing the school's discipline over his tardiness would be a naturalistic consequence he would then have to factor into his future decisions to ritualize.

Brianne expressed understanding and identified a goal of setting a boundary with Charlie around the morning routine. We agreed that she would no longer drive him to school in the morning, and it was up to him to walk himself to work and deal with the school's response should he arrived late to work or class.

I rated the past-week accommodation 4 out of 10 . 
Treating a Mother's Accommodation Behaviors of Her Adult Son's OCD:

Pragmatic Case Studies in Psychotherapy, http://pcsp.libraries.rutgers.edu

Volume 9, Module 1, Article 1, pp. 1-57, 02-17-13 [copyright by author]

\section{Session 3}

Brianne arrived to her third session in a very positive mood and reported that she hadn't driven Charlie to school at all during the week in addition to continuing to maintain her eveningtime boundary. She had been surprised to find that it made her anxious to be away from Charlie and that her attention was usually occupied wondering if Charlie was ritualizing. Together, Brianne and I examined what specific thoughts she had about Charlie performing his rituals that led to her anxiety. Brianne's thoughts centered around two themes: that Charlie's OCD would never get better if ritualized, and that he would damage or disturb the house if he was left alone to perform his rituals. I normalized Brianne's anxiety by explaining that it was very common for family members of individuals with OCD to become "emotionally over-involved" with their loved one's anxiety to the point where they begin to experience anxiety themselves. Oftentimes, these family members will similarly seek to reduce their own anxiety by assisting or reassuring their loved one with their rituals. Brianne stated that she was surprised to learn how much anxiety she had about Charlie's OCD and acknowledged that she would have to learn to cope with her own feelings about Charlie's OCD in order to create distance for herself. For homework, I asked her to track some of her anxiety thoughts related to Charlie's OCD during the week.

I rated the past-week accommodation 4 out of 10 .

\section{Session 4}

Brianne arrived at the fourth session reporting a high level of stress, feelings of anger and frustration toward Charlie and discouragement over her progress. Brianne reported that Charlie had been extremely anxious during the week, had been "back-stepping" continuously in the house and constantly seeking verbal and physical reassurance from her. Brianne suspected that Charlie's anxiety was elevated due to the fact that Brianne would be away the following week for an out-of-state bridal shower which Brianne was viewing as a mini-vacation. On several occasions over the week, Brianne had accommodated Charlie's OCD by taking over his responsibilities in the house or helping him avoid feared objects. Although she had continued to resist taking him to school, she admitted she was having thoughts about giving in and driving him again because he was showing up late. I reflected the way in which Brianne's anxiety and stress had become elevated as a result of Charlie being more anxious over the past week, resulting in increased rituals and accommodation. In the course of this discussion, I explained to Brianne that Charlie's OCD was not her fault and it was neither her responsibility nor within her control to stop his rituals. Brianne found the discussion on control and responsibility helpful and stated that she would try to remind herself of this while she was away on vacation.

I viewed Brianne’s week away from Charlie as being a critical period in Brianne’s treatment, as she was being afforded the opportunity to focus on her own needs for rest, relaxation, and enjoyment as well as expose herself to her urges to constantly monitor Charlie's behavior and affect. If Brianne could expose herself to the anxiety of being away from Charlie and not knowing how he was doing with his OCD, she could then begin to gradually shift her attention and energies to her own needs. I encouraged Brianne to think of her own self-care and 
Treating a Mother's Accommodation Behaviors of Her Adult Son's OCD:

need for relaxation while she was away from Charlie. For homework, I asked Brianne to practice thought-acceptance strategies such as visualizing the thought passing by her when she became anxious and uncertain about what Charlie was doing, and to attempt to avoid giving in to her anxiety by calling him or answering his calls. I also asked Brianne to limit her phone calls to and from Charlie to one per day while she was away.

I rated the past-week accommodation 7 out of 10 .

\section{Session 5}

After a week hiatus for Brianne's vacation, she arrived at the fifth session in a positive mood and reported that she had successfully handled her time away from Charlie. She had followed her homework assignment and limited her phone contact to one call per day, and perhaps most importantly stated that she felt less anxious and had an easier time attending to her vacation activities rather than worrying about what Charlie might be doing. She stated that she had really enjoyed catching up with friends and family at the bridal shower, and that it had really made her aware how much she had neglected these relationships over the past several years while dealing with Charlie's OCD. Brianne reported that she was surprised with how much easier it became for her over the week to focus on herself and her activities while on vacation.

Additionally, upon returning home Brianne was pleased to learn that Charlie had not ritualized more than usual and had functioned normally. Brianne stated that her time away from Charlie had helped her realize just how much attention she devotes to Charlie and $\backslash$ his OCD. She understood that her attention was valuable to Charlie and that it was likely one of his goals in performing his rituals. For homework, I asked Brianne to make a list of the pros and cons both for herself and Charlie, focusing on the consequences of deciding to engage with Charlie when he ritualized versus choosing to disengage and ignore his behavior.

I rated the past-week accommodation 3 out of 10 .

\section{Session 6}

In Brianne's sixth session, the focus was expanded to include the roles of other family members, particularly her husband given Brianne's report of feeling she was the only caregiver willing to set boundaries with Charlie. During the past week, Brianne and her husband had taken Charlie to the hospital for a doctor's appointment. This had been very difficult for Charlie, as hospitals still made him extremely anxious and were typically avoided. Brianne felt very proud of herself for encouraging Charlie to attend by using critical, non-hostile statements (e.g. "You don't want your OCD to keep you from doing something other people your age can do, right?") without overt reassurance. However, Brianne became frustrated when, upon arriving home from the hospital, her husband accommodated Charlie's request that he be driven back to the hospital and home again as part of a "back-stepping" ritual. Brianne objected and refused to participate, remaining at home while her husband drove Charlie. Brianne was given encouragement for both refusing to accommodate her son's OCD request and refusing to stay in the car while her husband drove Charlie back. This episode provided Brianne the opportunity to explore her feeling isolated against the OCD, particularly during times her husband would go to bed early in 
Treating a Mother's Accommodation Behaviors of Her Adult Son's OCD:

Pragmatic Case Studies in Psychotherapy, http://pcsp.libraries.rutgers.edu

Volume 9, Module 1, Article 1, pp. 1-57, 02-17-13 [copyright by author]

the evenings instead of remaining to help Brianne with Charlie or when her son Shane would complain to her about Charlie's rituals and then leave her to speak with Charlie. Brianne indicated that she believed it would be helpful for her husband to attend a session and learn about the work she had been doing, and we decided her husband would attend in three weeks when he had a free day in his schedule.

I rated the past-week accommodation 5 out of 10. This was higher than the previous week because Brianne had difficulty maintaining her agreed upon boundary for limited hugging with Charlie throughout the day.

\section{Session 7}

At the seventh session, Brianne arrived in a distressed mood and stated the previous week had been difficult as an old ritual of Charlie's had re-emerged, involving him taking prolonged showers. Brianne described that she had found it difficult to ignore Charlie's showering, particularly when she was in the house and could hear the water running. Brianne acknowledged that one possible reason this ritual had re-emerged was that Charlie knew it made her agitated and more likely to engage with him in the evening. Brianne and I reviewed a list of nonengagement strategies she could use in response to the ritual, including telling Charlie before the shower that if he went over a certain time limit she would turn off the hot water, or simply ignoring by going to bed.

The second half of the session was spent discussing some of the positives Brianne had identified that Charlie might begin to experience if household accommodation was reduced. Brianne believed that if she took a less active role with Charlie, it would encourage him to become more self-reliant and engage more with his peers, something she feared he would never be able to do because of his OCD. Brianne had been encouraged during the week when Charlie told her he was going to play basketball with a neighborhood friend, something she had never known him to do before. I asked Brianne to keep her desires for Charlie in mind whenever she was confronted with a decision to accommodate his OCD or provide reassurance.

I rated the past-week accommodation 4 out of 10.

\section{Session 8}

The eighth session was one of the most significant over the course of Brianne's treatment. At the outset, Brianne reported that she had been more successful in resisting engagement with Charlie's shower ritual and had decided to use the strategy of going outside to garden whenever she heard the shower go on because it took her away from the noise of the water. Along with this development, Brianne reported that she had begun to realize that the anxiety she felt towards Charlie extended to both her husband Jack and older son Shane, and she concluded that she frequently sacrificed her own needs and care due to worry about the family's overall functioning and cohesion. I validated this insight and normalized by informing Brianne that mothers often find themselves feeling they need to keep a family together, particularly when the family is attempting to cope with the presence of an illness in the household. I encouraged Brianne to use the remaining sessions of treatment to focus on ways in which she could practice 
self-care and allow herself to engage in enjoyable personal activities and relationships she had previously sacrificed. For instance, Brianne was encouraged to think of ways she could spend time with her son Shane outside of the house, as many of their interactions frequently centered on discussing issues related to Charlie and his rituals. Brianne thought about this for a minute and said that for homework she would call up a girlfriend whom she hadn't seen for some time and schedule a date to go out for food and drinks. Brianne felt better at the end of the session and excited about the opportunity to begin taking care of herself and rebuilding relationships with friends and family she had grown apart from.

I rated the past-week accommodation 3 out of 10 .

\section{Session 9}

The ninth session marked the arrival of Brianne's husband Jack into the treatment. The beginning of the session was focused on having Brianne and I fill Jack in on what Brianne had been working on during the treatment and what successes and challenges she had encountered. Brianne brought up the recent incident in which Jack had helped Charlie "back-step" to the hospital and used it to highlight ways in which she believed Jack was still accommodating. Jack indicated that he frequently chose to accommodate in order to prevent Charlie's anxiety from escalating, which would in turn further disrupt the household. I discussed some of the strategies Brianne had been using for dealing with Charlie’s anxiety.

Towards the end of the session, Brianne told Jack directly that she felt as if she was alone in dealing with Charlie's OCD around the house because of his tendency to withdraw and go to bed. Jack indicated that he hadn't known Brianne felt so alone in dealing with Charlie's OCD and recognized that it might be helpful if he supported Brianne's right to self-care by telling Charlie to give his mother space and time to herself. The couple left the session motivated to work together to support one another in resisting accommodation and devoting time for themselves away from Charlie.

I rated the past-week accommodation 3 out of 10.

\section{Session 10}

In the final session, Brianne and I reviewed the course of Brianne's treatment and highlighted many of the accomplishments she had made over the past three months. Brianne indicated that her relationship with Jack had improved since the last session, and reported that Jack had been asking Charlie to give his mother space to herself around the house at night. Furthermore, Brianne excitedly described how Charlie had begun to talk about wanting to look for a part-time job after his school semester ended. She stated that Charlie had never previously spoken about personal goals. Brianne indicated that she didn't believe Charlie was any more motivated to seek treatment for his OCD now than at the beginning of treatment, but she felt that this might change over time if she continued to resist engaging and accommodating his OCD.

Brianne reported that Charlie had told her he was glad she would no longer be coming in for treatment, believing that this was a sign that Charlie had noticed the change in her behavior 
and that he had been unhappy that she would no longer help him with his OCD. Finally, Brianne expressed her desire to continue in treatment with a new therapist at the anxiety clinic once her post-treatment study assessment was completed. She felt she had come very far in her treatment and identified areas for further work, including coping with her own feelings of anxiety in response to Charlie performing his rituals. Brianne reported that she felt less frustrated towards Charlie when he decided to ritualize because she had allowed herself to feel less guilty and responsible for his OCD. Brianne also indicated that she was enjoying reconnecting with relationships she believed she had sacrificed in the past in order to try and manage Charlie's OCD.

I rated her final past-week accommodation 2 out of 10.

\section{The Therapy Relationship}

As in any therapeutic relationship, the development of a positive, non-judgmental working alliance founded upon a sense of collaboration and mutual trust was deemed essential to the treatment outcome. In particular, I tried to remain sensitive to the fact that family members may experience an understandable degree of sensitivity and defensiveness when discussing the model of family accommodation and the negative impact on their loved one's OCD. For any therapist, there exists the risk that family members may not fully understand why treatment interventions are being directed at their behaviors rather than the OCD rituals, and consequently may come to view the therapist as an outsider to the family system who is attempting to "teach" them how to behave "better” towards their family member's OCD.

In working with Brianne and her family, I tried to focus on and have her write down personal examples of the ways in which she felt her increased attention and energy on Charlie's OCD had negatively impacted her own life, for instance her brief feelings of resentment towards Charlie or her sadness over the quality of her relationship with her husband Jack and son Shane. Then, in presenting the accommodation model, I attempted to use her own description of the consequences of accommodation to reinforce the benefits of changing her own behaviors in response to her son's rituals. Additionally, I attempted to encourage and reinforce Brianne for the tremendous amount of patience and resiliency she had already shown over the past several years in attempting to help her son and keep her family together, since it was vital to convey an understanding that individuals frequently choose to accommodate due to feelings of love and desire to protect their family member.

I again tried to use this approach when Brianne invited her husband Jack to the ninth session, knowing that given Brianne's report of his withdrawal inside the home he may have been sensitive to being "criticized" by a therapist for his disengagement with Charlie. My focus in this session was to elicit Jack's beliefs and feelings about Charlie's OCD and the quality of the family's interactions with Brianne accommodating rituals. My hope was that having Jack give a voice to his feelings would encourage both he and Brianne to begin speaking more directly with one another about their frustrations with each other and how they both could work together to help themselves, their family, and Charlie’s OCD. 
Independent of my efforts to present treatment information and interventions in a nonjudgmental fashion, Brianne proved to be highly motivated from the outset of treatment and extremely willing to examine her own role in the OCD process. On several occasions she openly voiced questions or concerns regarding something I had said, and took great pains to educate me on her history with Charlie and his OCD. It is very likely that the success Brianne experienced both during and after her 10-session treatment was largely due to her change motivation and willingness to learn about her own role in her son's OCD. Without her buy-in to the model of working to address her son's OCD through her own behavior, it is very likely that treatment would have been unsuccessful and Charlie would have remained unmotivated to address his OCD.

\section{THERAPY MONITORING AND USE OF FEEDBACK INFORMATION}

After each session I listened to an audiotape of the session and reflected on its content and process. This reflection was enhanced by supervision of each session with a senior-level, doctoral clinical psychologist. The reflection was used to (a) make a rating of the past-week's level of accommodation behaviors by Brianne (see Table 3); and (b) make any modification of the formulation or treatment plan that seemed necessary in order to meet the therapy's goals.

\section{CONCLUDING EVALUATION OF THE THERAPY'S PROCESS AND OUTCOME}

\section{Charlie's Outcomes}

As mentioned above, Charlie's intellectual limitations precluded him from completing the planned quantitative questionnaires to assess his anxiety, OCD, and motivation for change. However, at the post-treatment interview, Charlie agreed to sit down with the investigator and describe his experience while his mother was in treatment. He reported that he believed his mother had become "stricter" towards him in general while she was in treatment and cited her refusal to engage with him after 10:30pm as an example of this change. Charlie also indicated his belief that Brianne had been acting "stricter" towards his OCD and had noticed her "yelling” more often for him to stop his rituals. Charlie indicated that Brianne had explained to him why she had been acting stricter during treatment and that he agreed his mother probably "needed a break from him” occasionally and that he was okay with her taking time to herself.

When asked if he believed his OCD had become worse while his mother was in treatment, Charlie stated he felt it was about the same but that he had become more aware of it as a result of his mom ignoring him more often. Corresponding to Charlie's report that he had not become more anxious despite being more aware of his OCD, Brianne had reported at the last session that Charlie had not displayed an increase in tantrums or aggressive outbursts in response to her disengaging from his rituals and resisting his attempts at reassurance. When asked how he had been coping with his mom no longer helping him with his OCD, Charlie stated that he had turned to asking his father for help, such as with picking up items in his room from areas he didn't want to approach. Charlie then confirmed that although he believed his mother would 
Treating a Mother's Accommodation Behaviors of Her Adult Son's OCD:

Pragmatic Case Studies in Psychotherapy, http://pcsp.libraries.rutgers.edu

Volume 9, Module 1, Article 1, pp. 1-57, 02-17-13 [copyright by author]

continue ignoring his OCD and acting "strict and angry” towards him he did not desire treatment for his OCD at this time. At the end of the interview, Charlie was asked what advice he would give to someone he knew if they had OCD and needed help. Charlie responded that he would tell them to "ignore it" because being aware of it makes it worse.

\section{Brianne's Quantitative Outcomes}

As shown in Table 1, both Brianne's total scores and subscale scores of depression, anxiety, and stress on the DASS-21 - both throughout therapy and at post-therapy-were all within the normal 0-30 range. At the post-treatment interview, Brianne's WHOQOL-BREF quality of life score was $88^{\text {th }}$ percentile for physical health, $69^{\text {th }}$ for psychological health, $69^{\text {th }}$ for social relationships and $63^{\text {rd }}$ for environmental stress, all within the normal range.

Also shown in Table 1, Brianne's post-treatment FAS-IR accommodation score was 7, a $73 \%$ decrease from her pre-treatment score of 26. In terms of the mean of 12.1 for the 36 adult obsessive-compulsive patients and their primary caregivers on whom the measure was developed , Brianne's scores went from well above the mean at pre-therapy to below the mean at posttherapy. Specifically, Brianne displayed significant decreases in most domains of accommodation, especially item 3, "waiting for the patient"; item 7, "facilitating avoidance"; and item 9, "helping the patient with tasks of daily living or simple decisions."

Consistent with the results in Table 1 are my ratings shown in Table 3 . These are ratings of Brianne's past-week total accommodation behaviors made after each therapy session, from 0 , no presence of accommodation, to 5, moderate accommodating behaviors, to 10, highest level of accommodation behaviors. The results in Table 3 show a general decrease over the course of the 10 sessions. For example the average of the first 5 sessions was 4.6, and for the last five sessions, 3.4.

\section{Brianne's Qualitative Outcomes}

Brianne reported at the conclusion of treatment that she had significantly reduced her daily accommodation of Charlie's rituals and was continuing to work on limiting her reaction to Charlie's daily attempts for verbal and physical reassurance. Brianne had stopped driving Charlie to school in the morning when he was running late and had not facilitated Charlie's "backtracking” ritual throughout the duration of the treatment. She had maintained her evening-time boundary and stated she was continuing to focus her attention elsewhere when presented with evidence of Charlie ritualizing, for instance going outside to garden when he was repeating shower rituals.

While simultaneously decreasing accommodation behaviors, Brianne had begun to increase time spent on leisure activities and with friends and family relationships she had neglected over the past year. At the immediate end of treatment, Brianne indicated that she hoped to schedule a date night with her husband in the near future and felt free to leave Charlie alone in the house while she was away. She was also encouraged to see Charlie beginning to branch out by establishing friendships with children his age in the neighborhood and engaging in free-time leisure activities such as playing basketball in the local park. 
Finally, Brianne reported that her time in treatment had allowed her to realize just how much her own anxiety factored into her efforts to respond immediately to the needs of Charlie, her other son Shane, and her husband Jack in order to keep stability in the household. Specifically for Charlie, Brianne stated that understanding and accepting that she had limited responsibility and control for Charlie's rituals allowed her to divest herself from concern over whether he chose to engage in ritualistic behaviors. She reported feeling less frustrated and happier around the house, although she acknowledged believing she had more work to do in order to prevent herself from reverting back to old patterns.

\section{Jack and Shane's Qualitative Outcomes}

The outcome data for Jack and Shane are somewhat limited due to their not being directly included in the post-treatment assessment process. After attending the ninth session, Brianne reported that Jack had listened to her requests for assistance around the home and had started going to bed later in order to help her with Charlie in the evenings. Jack had even begun telling Charlie that he needed to leave his mother alone in the evening during "her time" but that he could spend time with his father before the family went to bed.

Brianne also stated that Jack was excited over their plans to make a future date night and agreed with Brianne's goal that the couple needed to work on spending more time alone together and trusting their children to get along without them. Brianne expressed mild amazement at the last session that Jack had begun assisting her with Charlie around the house as she had been asking him to help for some time to no avail. Brianne indicated she believed that it was helpful for Jack to hear from the therapist that he could help out with Charlie's OCD. Brianne also found helpful the discussion in her therapy session with Jack that both she and Jack could hear from each other that they both had the same goals for the family in relation to Charlie's OCD.

There did not appear to be new information on Shane's adjustment to his brother's OCD or Shane's relationship with his mother at the end of treatment. Brianne indicated several times throughout the treatment that she was aware her son Shane likely experienced feelings of resentment over her mother's attention to his brother and that she needed to spend more time with her older son. This is considered to be an area that the current treatment neglected to address, as Brianne was never given a homework assignment to spend time outside the home with Shane. However, at treatment termination Brianne continued to recognize the need to work on her relationship with Shane and indicated she would continue to move towards that goal as her treatment continued.

\section{Follow-Up}

After the conclusion of treatment and the collection of post-treatment assessment data, Brianne did in fact return to therapy with a new clinician at the Anxiety Clinic in order to continue working on her accommodation and self-care goals. Approximately four months after the conclusion of treatment, I was contacted by this new therapist and informed that Brianne was continuing to progress in treatment and that she had remained steadfast in resisting accommodating Charlie's OCD. Furthermore, the clinician informed me that Charlie's 
Treating a Mother's Accommodation Behaviors of Her Adult Son's OCD:

The Case of "Brianne" and "Charlie"

J. Marinchak

Pragmatic Case Studies in Psychotherapy, http://pcsp.libraries.rutgers.edu

Volume 9, Module 1, Article 1, pp. 1-57, 02-17-13 [copyright by author]

motivation to enter into treatment had begun to increase and that the family was looking into the possibility of having Charlie begin individual therapy for his OCD.

\section{Discussion}

\section{$\underline{\text { Brianne's Outcome }}$}

The primary purpose of this case study was to examine whether a brief intervention targeted to an individual living with an adult family member diagnosed with OCD could be effective in reducing accommodation behaviors and improving that individual's overall quality of life. Additionally, the case study aimed to examine whether such decreases in family accommodation might in turn lead to an increase in willingness to seek out OCD treatment for the diagnosed family member. Based upon the quantitative and qualitative results at posttreatment, the primary hypothesis that treatment would lead to decreased accommodation and improved quality of life for the patient Brianne was supported. Over the ten-week course of treatment, Brianne experienced a substantial decrease in her accommodation behaviors towards her son Charlie's OCD and an improvement in communication with her husband Jack and her older son Shane. During treatment, Brianne strove to reduce her seemingly excessive responsibilities to her son's OCD and to increase her focus on her own needs and the needs of her Jack and Shane.

During the first few sessions of therapy, Brianne expressed significant feelings of stress, frustration, and anger towards Charlie and her demanding role in having to accommodate him. At the end of therapy, she reported important improvement in her overall stress and quality of life, better relationships with her husband Jack and older son Shane, and a commitment to focus more on her leisure time activities and her outside friendships.

At the same time these qualitative reports within the therapy were not consistent with Brianne's scores on the standardized measures of depression, anxiety, and quality of life (see the DASS-21 and WHOQOL scores in Table 1). Specifically, on these measures Brianne scored well within the normal range at the beginning of therapy, and remained there at the conclusion of treatment, thus showing no change over the course of therapy since she began at a high level of mental health. There appear to be a at least two possible reasons as to why this was. First, it could be that Brianne compartmentalized her relationship with Charlie while filling out her standardized measures, such that she put her stress from her relationship with Charlie into a separate category and filled out her forms thinking about aspects of her current life outside of Charlie and his OCD.

Second, it could also be that Brianne was motivated to appear "normal” and "in control" in front of the interviewer whom Brianne knew would also be working as her therapist in the study. Brianne stated at the beginning of the study that this would be her first time in treatment, and it is probable that her expectations for therapy led her to have some concern over being judged by the therapist. In this regard, it is noteworthy that during the pre-treatment assessment Brianne was very hesitant in discussing her feelings of anger towards Charlie, specifically one incident in particular in which she "kidnapped” Charlie's toys in retaliation for his emotional 
Treating a Mother's Accommodation Behaviors of Her Adult Son's OCD:

Pragmatic Case Studies in Psychotherapy, http://pcsp.libraries.rutgers.edu

Volume 9, Module 1, Article 1, pp. 1-57, 02-17-13 [copyright by author]

outburst. It is very possible that my efforts to normalize Brianne's reactions to Charlie's OCD and create a non-judgmental atmosphere during the therapy sessions helped Brianne "let her guard down" and more accurately report her current distress and functioning.

Although Brianne experienced a benefit from her short time in therapy, she indicated at its conclusion that additional sessions were necessary to consolidate her treatment gains and continue working towards her goals. Thus, at least in this case, it seems that a ten-session treatment, while helpful, was not a sufficient treatment dose for accommodating the family systems in which the OCD had been present for several years.

\section{Charlie's Outcome}

While the primary goal of the therapy was met in terms of reducing Brianne's accommodation and increasing her own self-care and sense of well being, the secondary goal of improved OCD treatment motivation for Charlie at post-treatment was not supported. Over the course of the study, Charlie acknowledged a change in his mother's attitude and behavior towards his OCD, and Brianne reported noticing Charlie describe an increased awareness of his OCD and the impact of his anxiety on his behavior. However, at the conclusion of treatment Charlie reported no change in his level of motivation for OCD treatment and indicated he had attempted to incorporate his father's help with his OCD in response to his mother's refusal. On the other hand, it is noteworthy, as mentioned above in the Follow Up section, that four months after the end of Brianne's therapy Charlie's motivation to enter into treatment for himself had begun to increase and that the family was looking into the possibility of having Charlie begin individual therapy for his OCD.

There are several possibilities for the lack of change in Charlie's level of motivation at the end of Brianne's therapy. Perhaps Brianne's post-treatment level of accommodation, while decreased, was still too elevated to allow Charlie to experience sufficient environmental consequences as a result of his rituals to warrant treatment. It may also be that any effect that decreased accommodation had on treatment motivation would have taken a longer period of time to develop and therefore an assessment immediately post-treatment was too soon to detect impact on motivation - as suggested by an increase in Charlie's motivation for treatment at fourmonth follow-up. To this point, several of the changes Brianne reported noticing in Charlie over the brief course of treatment, such as socializing with a peer outside of the home and verbalizing his desire for short-term employment, could also represent signs of developmental growth in Charlie that may one day become incompatible with his OCD and reliance on rituals. In addition, Charlie appeared to suggest that he had become more aware of his OCD in response to reduced accommodation, and this increased awareness might serve as a precursor for a future desire to seek treatment, since it would have become more difficult for him to ignore his illness. Finally, given the reciprocal nature of Charlie's OCD and Brianne's accommodation, it may be the case that Charlie, with the aid of therapy, could learn to ignore his obsessional thoughts in the same way that his mother learned to do in her own therapy. To this end, Brianne stated at the termination of treatment that she felt empowered to help Charlie deal with his OCD in a new way, namely by encouraging him to resist his urge to perform his compulsions and experience his anxiety. 
Treating a Mother's Accommodation Behaviors of Her Adult Son's OCD:

The Case of "Brianne" and "Charlie"

J. Marinchak

Pragmatic Case Studies in Psychotherapy, http://pcsp.libraries.rutgers.edu

Volume 9, Module 1, Article 1, pp. 1-57, 02-17-13 [copyright by author]

\section{The Four-Factor Model of Assessment and Intervention}

With the use of a systematic case study design (Fishman, 2005), it is possible to examine in depth the course of treatment and explore which factors may have been instrumental in creating positive therapeutic change. One of those factors was the use of Petronko, Harris, \& Kormann's (1994) four-factor model of assessment and intervention. Included were the levels of Brianne as an individual, Brianne as a caretaker/mother, Charlie's home and school environments, and the family system. The use of the four-factor model allowed for the creation of a treatment plan designed to intervene at multiple systemic levels impacting Brianne, Charlie, Charlie's OCD, and the two other members of the nuclear family, husband Jack and older brother Shane. Although the therapy treated Brianne at an individual level (with the exception of Brianne's one conjoint session with husband Jack), the four-factor perspective provided evidence that the OCD accommodation involved the entire family system and negatively impacted all involved. Therefore, a significant portion of the intervention focused on raising Brianne's awareness of the systemic impact of accommodation, such as how her engagement with Charlie's OCD prohibited his social and occupational development and resulted in negative feelings and withdrawal in Brianne, Jack, and Shane. The four-factor model also enabled Brianne and the therapist to identify potential environmental resources that she could utilize to assist in coping with Charlie's OCD, such as relying on school officials to introduce negative consequences for Charlie, or assertively requesting her husband's assistance in creating and maintaining boundaries within the home.

\section{Charlie's Dual Diagnosis Status}

Additionally, the use of a systematic case-study perspective proved beneficial given the nature of Charlie's dual diagnosis. There has been very little research conducted on family accommodation in households with dually diagnosed OCD individuals. In the present study, qualitative data gathered using the case study approach allowed for a direct comparison on the nature and impact of family accommodation in a family with a dually diagnosed individual such as Charlie with accommodation described in the OCD literature. It is important to note that Brianne's appeared to accommodate Charlie's OCD in similar ways (e.g. taking over his family responsibilities) and for similar reasons (e.g. emotional over-involvement) as those described in the OCD literature. Brianne's improvement during treatment and lack of decompensation in light of reduced accommodation provide some initial evidence that accommodating families with dually diagnosed OCD individuals can receive the same benefits from reducing accommodating behaviors as non-dual diagnosis families. In addition, there was no evidence to suggest that individuals with co-occurring developmental disorders experience different OCD treatment outcomes. To this point, it is noteworthy that Charlie, as expected, did not experience a significant increase in his OCD or display acting out behaviors in response to his mother's reduced accommodation.

It is important to note that in the current case study a decision was made to include a family in which OCD co-occurred with developmental issues, which was different from my original intention to recruit for an individual with OCD who had minimal Axis-I comorbidities, in order to reduce complexity. However, the decision was made to include Brianne and her 
Treating a Mother's Accommodation Behaviors of Her Adult Son's OCD:

Pragmatic Case Studies in Psychotherapy, http://pcsp.libraries.rutgers.edu

Volume 9, Module 1, Article 1, pp. 1-57, 02-17-13 [copyright by author]

family due to the clear impact of OCD on the household, the significant level of accommodation behaviors by Brianne, and the belief that the uniqueness of the case would fit with the case-study approach. A benefit of such a family-inclusive treatment approach was that it assisted the therapist in utilizing additional resources inside the home and external to the identified patient to assist the patient in pursuing her goals. For instance, by gathering information on Jack's accommodation role and inviting him into the treatment, Brianne and I were able to recruit him as an ally toward the goal of helping Brianne create boundaries inside the home and separate herself from Charlie.

\section{$\underline{\text { Patient-Specific Factors }}$}

While it is encouraging to see that a brief, 10-session course of therapy can provide a benefit for accommodating family members, it is also likely that several patient-specific variables factored into the course of treatment and overall results. Specifically, although never officially assessed quantitatively, Brianne's pre-treatment levels of motivation for therapy and awareness of her role in accommodating her son's OCD were quite high. From the moment I described the nature of the therapy, Brianne reported excitement over entering into treatment and a firm willingness to examine and correct her own thinking patterns and behaviors as they related to Charlie's OCD. At no point did I have to utilize motivational enhancement techniques with Brianne, and there was never a disagreement over targeting treatment intervention towards Brianne rather than Charlie. In many ways, Brianne's motivation and self-awareness of her accommodation may be unique, as the clinical literature reports that many family members typically accommodate out of a belief they are helping their loved one and may not fully realize or accept the negative impact of their actions. In future such cases, therapists may need to devote more time in the beginning of treatment to resolving ambivalence, explaining why the treatment will focus on changing the client's behaviors rather than their loved one's rituals, and reinforcing the OCD model highlighting the long-term negative impact accommodation has on OCD. Therefore, it seems important that in future cases, therapists looking to work directly with OCD family members should routinely assess for motivation and accommodation-awareness at the outset of treatment, and be prepared to plan for more than ten sessions of treatment should these issues need be addressed.

Lastly, it is important to discuss the manner in which Brianne coped with her own feelings of anxiety and responsibility surrounding Charlie's OCD during the course of her treatment. In accordance with previous research findings of family member's tendency to become over-involved emotionally with their loved ones' OCD (Van Noppen \& Steketee, 2009), Brianne would often begin to feel anxious when Charlie ritualized, and her subsequent attempts to accommodate during these occasions resulted in a decrease of her own anxiety, thus negatively reinforcing her accommodation behaviors. Initially, she was surprised that her own emotional state could have been so closely associated with her son's. However, a monitoring of her anxious thinking revealed that Brianne held the mistaken belief that Charlie would never stop ritualizing without her help. This insight into her accommodation subsequently led Brianne to the understanding that she adopted the caretaker role with all her family members as a result of her anxiety over their health and well-being. Once this connection had been made, Brianne committed herself to being less emotionally reactive and hypersensitive towards her family 
members generally, and to Charlie and his OCD, specifically. This commitment was viewed as a major treatment accomplishment, as it began to allow Brianne the freedom to pursue goals of practicing self-care and devoting time to herself that had gone neglected over the years prior to her therapy.

\section{Conclusion}

The results of the current study suggest that providing a brief, behavioral treatment to a family member can be an effective method of reducing OCD accommodation and improving quality of life within the household. While the treatment did not result in an increase in OCD treatment-seeking motivation, it also did not increase the OCD family member's level of anxiety and aggressive outbursts; and it is possible that a higher dose of treatment (i.e., more sessions) or simply the passage of time would result in greater motivational influence, with some evidence at follow-up confirming this latter possibility. Future case studies should expand on the current one by incorporating larger, more diverse samples and different patient-family member dyads, such as providing treatment to spouses or siblings in addition to mothers. Additionally, case study knowledge should be complemented by the use of randomized, controlled experimental designs for establishing the efficacy of a family-member-centered treatment approach. Finally, researchers should examine whether accommodating family members would derive equal benefit from treatment in the presence of different OCD subtypes and levels of symptom severity. 


\section{REFERENCES}

Albert, U., Bogetto, F., Maina, G., Saracco, P., Brunatto, C., \& Mataix-Cols, D. (2010). Family accommodation in obsessive-compulsive disorder: Relation to symptom dimensions, clinical and family characteristics. Psychiatry Research, 179, 204-211

Albert, U., Salvi, V., Saracco, P., Bogetto, F., \& Maina, G. (2007). Health-related quality of life among first-degree relatives of patients with obsessive-compulsive disorder in Italy. Psychiatric Services, 58, 970-976.

American Psychiatric Association (2000). Diagnostic and statistical manual of mental disorders ( $4^{\text {th }}$ ed., text revision). Washington, DC: Author.

Amir, N., Freshman, M., \& Foa, E. B. (2000). Family distress and involvement in relatives of obsessive-compulsive disorder patients. Journal of Anxiety Disorders, 14(3), 209-217.

Brown, T. A., Chorpita, B. F., Korotitsch, W., \& Barlow, D. H. (1997). Psychometric properties of the Depression Anxiety Stress Scales (DASS) in clinical samples. Behaviour Research and Therapy, 47, 710-715.

Brown, T. A., DiNardo, P. A., \& Barlow, D. H. (1994). Anxiety disorders interview schedule for DSM-IV: Adult version, client interview schedule. San Antonio, TX: The Psychological Corporation.

Brown, T. A., DiNardo, P. A., Lehman, C. L., \& Campbell, L. A. (2001). Reliability of DSM-IV anxiety and mood disorders: Implications for the classification of emotional disorders. Journal of Abnormal Psychology, 110(1), 49-58.

Calvocoressi, L., Lewis, B., Harris, M., Goodman, W. K., Trufan, S. J., McDougle, C. J., \& Price, L. H. (1995). Family accommodation in obsessive compulsive disorder. American Journal of Psychiatry, 152, 441-443.

Calvocoressi, L., Mazure, C. M., Kasl, S. V., Skolnick, J., Fisk, D., Vegso, S. J., Van Noppen, B.L., \& Price, L.H. (1999). Family accommodation of obsessive-compulsive symptoms: Instrument development and assessment of family behavior. http://psycnet.apa.org/index.cfm?fa=search.displayRecord\&id=87D29FD2-05D1-41E998A9-B713AF801555\&resultID=1\&page=1\&dbTab=all. Journal of Nervous and Mental Disease, 187, 636-642.

Chambless, D. L. \& Steketee, G. (1999). Expressed emotion and behavior therapy outcome: a prospective study with obsessive-compulsive and agoraphobic outpatients. Journal of Consulting and Clinical Psychology, 67, 658-665.

Cooper, M. (1996). Obsessive compulsive disorder: Effects on family members. American Journal of Orthopsychiatry, 66, 296-304.

Dattilio, F. M., Edwards, D. J., \& Fishman, D. B. (2010). Case studies within a mixed methods paradigm: Toward a resolution of the alienation between researcher and practitioner in psychotherapy research. Psychotherapy Theory, Research, Practice, Training, 47, 427441.

Dozois, D. J. A., Westra, H. A., Collins, K. A., Fung, T. S., \& Garry, J. K. F. (2004). Stages of change in anxiety: psychometric properties of the University of Rhode Island Change Assessment (URICA) scale. Behaviour Research and Therapy, 42, 711-729.

Fadden, G., Kuipers, L., \& Bebbington, P. (1987). The burden of care: the impact of functional psychiatric illness on the patient's family. British Journal of Psychiatry, 150, 285-292. 
Treating a Mother's Accommodation Behaviors of Her Adult Son's OCD:

The Case of "Brianne" and "Charlie"

J. Marinchak

Pragmatic Case Studies in Psychotherapy, http://pcsp.libraries.rutgers.edu

Volume 9, Module 1, Article 1, pp. 1-57, 02-17-13 [copyright by author]

Fishman, D. B. (2005). Editor's introduction to PCSP - From single case to database: A new method for enhancing psychotherapy practice. Pragmatic Case Studies in Psychotherapy, 1(1), Article 2, 1-50.

Franklin, M. E. \& Foa, E. B. (2008). Obsessive-compulsive disorder. In D. H. Barlow (Ed.), Clinical handbook of psychological disorders: A step-by-step treatment manual ( $4^{\text {th }}$ ed., pp. 164-215). New York: Guilford Press.

Geffken, G. R., Storch, E. A., Duke, D. C., Monaco, L., Lewin, A. B., \& Goodman, W. K. (2006). Hope and coping in family members of patients with obsessive-compulsive disorder. Anxiety Disorders, 20, 614-629.

Goodman, W. K., Price, L. H., Rasmussen, S. A., Mazure, C., Fleischmann, R. L., Hill, C. L., ...Charney, D. S. (1989). The Yale-Brown Obsessive Compulsive Scale. I. Development, use, and reliability. Archives of General Psychiatry, 46, 1006-1011.

Issakidis, C. \& Andrews, G. (2002). Service utilization for anxiety in an Australian community sample. Social Psychiatry and Psychiatric Epidemiology, 37, 153-163.

Jacobson, N. S. \& Truax, P. (1991). Clinical significance: A statistical approach to defining meaningful change in psychotherapy research. Journal of Consulting and Clinical Psychology, 59, 12-19.

Jenike, M. A. (2004). Obsessive-compulsive disorder. New England Journal of Medicine, 350, 259-265.

Koran, L. M. (2000). Quality of life in obsessive-compulsive disorder. Psychiatric Clinics of North America, 23, 509-517.

Koran, L. M., Thienemann, M. L., \& Davenport, R. (1996). Quality of life for patients with obsessive-compulsive disorder. American Journal of Psychiatry, 153, 783-788.

Livingston-Van Noppen, B., Rasmussen, S., Eisen, J., \& McCartney, L. (1990). Family function and treatment in obsessive compulsive disorder. In M. Jenike, L. Baer, W. Minichiello (Eds.), Obsessive compulsive disorder: Theory and management (2nd ed. 325-340.) Chicago: Yearbook Medical Publishers.

Lovibond, S. H., \& Lovibond, P. F. (1995). Manual for the Depression Anxiety Stress Scales (2 ${ }^{\text {nd }}$ ed.) Sydney, Australia: Psychology Foundation.

Magliano, L., Tosini, P., Guarneri, M., Marasco, C., \& Catapano, F. (1996). Burden on the families of patients with obsessive-compulsive disorder: A pilot study. European Psychiatry, 11, 192-197.

Maltby, N. \& Tolin, D. F. (2003). Overview of treatments for OCD and spectrum conditions: Conceptualization, theory, and practice. Brief Treatment and Crisis Intervention, 3, 127144.

Maltby, N. \& Tolin, D. F. (2005). A brief motivational intervention for treatment-refusing OCD patients. Cognitive Behaviour Therapy, 34, 176-184.

March, J. S., \& Mulle, K. (1998). OCD in Children and Adolescents: A Cognitive-Behavioral Treatment Manual. New York: Guilford Press.

McConnaughy, E. A., Prochaska, J. O., \& Velicer, W. F. (1983). Stages of change in psychotherapy measurement and sample profiles. Psychotherapy: Theory, Research, and Practice. 20, 368-375.

Persons, J. B. (2008). The Case Formulation Approach to Cognitive-Behavior Therapy. New York: Guilford Press. 
Treating a Mother's Accommodation Behaviors of Her Adult Son's OCD:

The Case of "Brianne" and "Charlie"

J. Marinchak

Pragmatic Case Studies in Psychotherapy, http://pcsp.libraries.rutgers.edu

Volume 9, Module 1, Article 1, pp. 1-57, 02-17-13 [copyright by author]

Peterson, D. R. (1991). Connection and disconnection of research and practice in the education of professional psychologists. American Psychologist, 40, 441-451.

Petronko, M. R., Harris, S. L., \& Kormann, R. J. (1994). Community-based behavioral training approaches for people with mental retardation and mental illness. Journal of Consulting and Clinical Psychology, 62, 49-54.

Piacentini, J., Bergman, R. L., Keller, M., \& McCracken, J. (2003). Functional impairment in children and adolescents with obsessive-compulsive disorder. Journal of Child and Adolescent Psychopharmacology, 13, 61-70.

Rasmussen, S. A., \& Eisen, J. L. (1992). The epidemiology and clinical features of obsessive compulsive disorder. Psychiatric Clinics of North America, 15, 743-758.

Renshaw, K. D., Steketee, G., \& Chambless, D. L. (2005). Involving family members in the treatment of OCD. Behavior Therapy, 34, 164-175.

Riccardi, C. J., Timpano, K. R., \& Schmidt, N. B. (2010). A case study perspective on the importance of motivation in the treatment of obsessive compulsive disorder. Clinical Case Studies, 9, 273-284.

Shafran, R. \& Ralph, J. (1995). Obsessive-compulsive symptoms and the family. Bulletin of the Menninger Clinic, 59, 472-479.

Simpson, H. B. \& Zuckoff, A. (2011). Using motivational interviewing to enhance treatment outcome in people with obsessive-compulsive disorder. Cognitive and Behavioral Practice, 18, 28-37.

Skevington, S. M., Lotfy, M., \& O’Connell, K. A. (2004). The World Health Organization’s WHOQOL-BREF quality of life assessment: Psychometric properties and results of the international field trial. Quality of Life Research, 13, 299-310.

Steketee, G. (1993). Social support and treatment outcome of obsessive compulsive disorder at 9-month follow-up. Behavioural Psychotherapy, 21, 81-95.

Steketee, G. (1997). Disability and family burden in obsessive-compulsive disorder. Canadian Journal of Psychiatry, 42, 919-928.

Steketee, G., \& Pruyn, N. A. (1998). Families of individuals with obsessive-compulsive disorder. In R. P. Swinson, M. M. Antony, S. Rachman, \& M. A. Richter (Eds.), ObsessiveCompulsive Disorder: Theory, Research, and Treatment (pp. 120-140). New York: Guilford Press.

Steketee, G. \& Van Noppen, B. (2003). Family approaches to treatment for obsessive compulsive disorder. Revista Brasileira de Psiquiatria, 25, 43-50.

Storch, E. A., Geffken, G. R., Merlo, L. J., Jacob, M. L., Murphy, T. K., Goodman, W. K., et al. (2007). Family accommodation in pediatric obsessive-compulsive disorder. Journal of Clinical Child and Adolescent Psychology, 36, 207-216.

Storch, E. A., Larson, M. J., Muroff, J., Caporino, N., Geller, D., Reid, J. M., et al. (2010). Predictors of functional impairment in pediatric obsessive-compulsive disorder. Journal of Anxiety Disorders, 24, 275-283.

Storch, E. A., Merlo, L. J., Larson, M. J., Marien, W. E., Geffken, G. R., Jacob, M. L., et al. (2008). Clinical features associated with treatment-resistant obsessive compulsive disorder. Comprehensive Psychiatry, 49, 35-42.

Van Noppen, B. \& Steketee, G. (2009). Testing a conceptual model of patient and family predictors of obsessive compulsive disorder (OCD) symptoms. Behaviour Research and Therapy, 47, 18-25. 
Weissman, M. M., Bland, R. C., Canino, G. J., Greenwald, S., Hwu, H. G., Lee C.K, ..., \& Wickramaratne, P. J. (1994). The cross-national epidemiology of obsessive compulsive disorder: The cross national collaborative group. Journal of Clinical Psychiatry, 55 (Suppl. 3), 5-10.

Woody, S. R., Steketee, G., \& Chambless, D. L. (1995). Reliability and validity of the YaleBrown Obsessive Compulsive Scale. Behaviour Research and Therapy, 33, 597-605.

Zohar, A. H. (1999). The epidemiology of obsessive-compulsive disorder in children and adolescents. Child and Adolescent Psychiatric Clinics of North America, 8, 445-460. 
Pragmatic Case Studies in Psychotherapy, http://pcsp.libraries.rutgers.edu

Volume 9, Module 1, Article 1, pp. 1-57, 02-17-13 [copyright by author]

Table 1. Standardized Measures Employed with Brianne

\begin{tabular}{|c|c|c|c|}
\hline Measure & Clinical Meaning of Scores & Pre-Therapy* & Post-Therapy* \\
\hline $\begin{array}{l}\text { Depression \& Anxiety (DASS-21); } \\
\text { (higher scores = higher pathology) }\end{array}$ & $\begin{array}{l}\text { Range for Normal Population }= \\
0-30\end{array}$ & Total $=7$ & Total $=5$ \\
\hline $\begin{array}{l}\text { Physical Health (WHOQOL); } \\
\text { (higher percentiles=better quality of } \\
\text { life) }\end{array}$ & $\begin{array}{l}\text { Range for normal population = } \\
\text { above 50th percentile }\end{array}$ & $81^{\text {st }}$ percentile & $88^{\text {th }}$ percentile \\
\hline $\begin{array}{l}\text { Psychological Health (WHOQOL); } \\
\text { (higher percentiles=better quality of } \\
\text { life) }\end{array}$ & $\begin{array}{l}\text { Range for normal population = } \\
\text { above 50th percentile }\end{array}$ & $81^{\text {st }}$ percentile & $69^{\text {th }}$ percentile \\
\hline $\begin{array}{l}\text { Social Relationships (WHOQOL); } \\
\text { (higher percentiles=better quality of } \\
\text { life) }\end{array}$ & $\begin{array}{l}\text { Range for normal population = } \\
\text { above 50th percentile }\end{array}$ & $69^{\text {th }}$ percentile & $69^{\text {th }}$ percentile \\
\hline $\begin{array}{l}\text { Enviromental Stress (WHOQOL); } \\
\text { (higher percentiles=better quality of } \\
\text { life) }\end{array}$ & $\begin{array}{l}\text { Range for normal population = } \\
\text { above 50th percentile }\end{array}$ & $69^{\text {th }}$ percentile & $63^{\text {rd }}$ percentile \\
\hline $\begin{array}{l}\text { Section } 2 \text { of the Family } \\
\text { Accommodation for Obsessive- } \\
\text { Compulsive Disorder (FAS-IR); } \\
\text { (higher scores=more family } \\
\text { accommodation) }\end{array}$ & $\begin{array}{l}\text { For } 36 \text { adult obsessive- } \\
\text { compulsive patients and their } \\
\text { primary caregivers on whom } \\
\text { the measure was developed: } \\
\text { Mean }=12.1 \mathrm{SD}=9.79^{5}\end{array}$ & 26 & 7 \\
\hline
\end{tabular}

* The DASS-21 was also completed by Brianne during every other session, and all these scores fell within the 0-30 range, with no elevation of the depression, anxiety and stress subscales. 


\section{Table 2. Outline of 10-Session Family-Member Oriented Treatment Manual}

Session 1

- Check-In

- Motivational Assessment

o motivational enhancement techniques (if needed)

- Elaboration of short-term/long-term therapy goals

- OCD Accommodation Psycho-Education

- Homework Assignment

Session 2

- Check-In

- Homework Review

o Use problem-solving and motivational enhancement if not completed

- Discuss role of naturalistic consequences for OCD ritual behaviors

o Elicit examples of missed opportunities for consequences due to accommodation

- Discuss opportunities for in-home boundary setting

- Homework Assignment

Session 3

- Check-In

- Homework Review

- Introduce role of automatic thoughts and beliefs about OCD in accommodation

o Focus on thoughts and beliefs about family member experiencing "anxiety”

o Introduce concept of emotional over-involvement

- Assign homework of thought monitoring and continued boundary setting

Session 4

- Check-In

- Homework Review

o Examine reasons for lapse in previously assigned homework and re-assign

- Set behavioral goals for patient's upcoming vacation

0 Introduce concept of patient self-care in conjunction with accommodation reduction

o Normalize reaction of increased anxiety and OCD in response to patient leaving

- Assign homework assignments for patient to practice while on vacation

Session 5

- Check-In

- Homework Review

- Review patient's vacation

o Highlight descrepencies in patient's beliefs about impact on OCD of her being away

0 Bring attention to positive impact for patient of creating space apart from OCD

- Homework Assignment

o Enhance awareness of positive and negative impact of accommodation by creating pros/cons list 


\section{Table 2 (continued)}

\section{Session 6}

- Check-In

- Homework Review

- Begin examination of husband and older son's role in OCD accommodation

o Impact of their withdrawal on patient

o Link her OCD accommodation goals with her goals for her family relationships

- Assign homework

o Request for husband to attend next session to communicate patient's feelings about OCD and desire for family to make systematic changes

Session 7

- Check-In

- Homework Review

- Problem solving re-emergence of old ritual

- Review negative impact of accommodation on Charlie's development and individualization

o Assist patient in articulating developmental goals for her sign

o Link boundary setting and reduced accommodation to developmental goals

- Homework Assignment

Session 8

- Check-In

- Homework Review

- Examine patient's self-perceived role as family care-giver and negotiator

o Impact of personal anxiety

o Relationshsip to her quality-of-life

- Articulate patient goals for relationships with friends and family outside of her younger son

- Homework Assignment

Session 9

- Check-In

- Homework Review

- Explore impact of OCD and accommodation with patient and her husband

o Facilitate husband's expression of thoughts and beliefs about his son's OCD and his wife's past accommodation

o Foster communication between couple on OCD goals and desires for their relationship

o Highlight patient efforts over the course of treatment

- Explore couple's motivation to work together outside of treatment on mutual goals

- Assign Homework 
Treating a Mother's Accommodation Behaviors of Her Adult Son's OCD:

The Case of "Brianne" and "Charlie"

J. Marinchak

Pragmatic Case Studies in Psychotherapy, http://pcsp.libraries.rutgers.edu

Volume 9, Module 1, Article 1, pp. 1-57, 02-17-13 [copyright by author]

\section{Table 2 (continued)}

\section{Session 10}

- Check-In

- Homework Review

- Conduct review of treatment with patient

o Re-analysis of short-term/long-term goals

o Highlight areas of improvement and areas still in need of work

o Identify any new problems or goals that have emerged from treatment

- Conduct brief relapse prevention on any problem areas

o Coordinate continued treatment if patient desires

- Conclude Treatment 
Treating a Mother's Accommodation Behaviors of Her Adult Son's OCD:

The Case of "Brianne" and "Charlie"

J. Marinchak

Pragmatic Case Studies in Psychotherapy, http://pcsp.libraries.rutgers.edu

Volume 9, Module 1, Article 1, pp. 1-57, 02-17-13 [copyright by author]

Table 3. Therapist Rating of Brianne's

Past-Week Total Accommodation Behaviors

(a score of 10 denotes the highest possible level of accommodation behaviors; 5, moderate accommodating behaviors; and 0 , no presence of accommodation within the home)

\begin{tabular}{|c|c|c|c|c|c|c|c|c|c|c|}
\hline Measure & Week & Week & Week & Week & Week & Week & Week & Week & Week & Week \\
$\mathbf{1}$ & $\mathbf{2}$ & $\mathbf{3}$ & $\mathbf{4}$ & $\mathbf{5}$ & $\mathbf{6}$ & $\mathbf{7}$ & $\mathbf{8}$ & $\mathbf{9}$ & $\mathbf{1 0}$ \\
\hline $\begin{array}{c}\text { Therapist Rating of } \\
\text { Past-Weekly } \\
\text { Accommodation }\end{array}$ & 5 & 4 & 4 & 7 & 3 & 5 & 4 & 3 & 3 & 2 \\
\hline
\end{tabular}




\title{
Appendix 1
}

\section{FAMILY ACCOMMODATION SCALE \\ FOR \\ OBSESSIVE-COMPULSIVE \\ DISORDER \\ Interviewer-Rated (FAS-IR)}

\author{
Developed by:
}

\section{Lisa Calvocoressi, Ph.D., Carolyn M. Mazure, Ph.D., Barbara Van Noppen, Ph.D., and Lawrence H. Price, M.D.}

*** The PCSP journal thanks Dr. Calvocoressi and colleagues for permission to reproduce the FAS-IR.*** 


\title{
FAMILY ACCOMMODATION SCALE FOR OBSESSIVE-COMPULSIVE DISORDER Interviewer-Rated (FAS-IR)
}

\author{
Developed by \\ Lisa Calvocoressi, Ph.D., Carolyn M. Mazure, Ph.D., Barbara Van Noppen, Ph.D., and \\ Lawrence H. Price, M.D.
}

\section{Copyright and Permissions}

The Family Accommodation Scale for Obsessive Compulsive Disorder Copyright (C) 1999 by Lisa Calvocoressi, Ph.D., Carolyn M. Mazure, Ph.D., Barbara Van Noppen, Ph.D., and Lawrence H. Price, M.D.

The Family Accommodation Scale for Obsessive Compulsive Disorder includes a modified version of the Yale Brown Obsessive Compulsive Scale (YBOCS) Checklist and items based on the YBOCS scale, copyright @ 1986, 1989, with permission.

\section{References}

Calvocoressi L, Mazure CM, Kasl SV, Skolnick J, Fisk D, Vegso SJ, Van Noppen BL, Price LH: Family accommodation of obsessive-compulsive symptoms: Instrument development and assessment of family behavior. The Journal of Nervous and Mental Disease 1999;187:636-642.

Calvocoressi L, Mazure CM, Van Noppen B, Price, LH. The family accommodation scale for obsessive-compulsive disorder. In: Steketee G. Overcoming Obsessive-Compulsive Disorder: A Behavioral and Cognitive Protocol for the Treatment of OCD. Oakland, CA: New Harbinger Publications, Inc.;1999:185-200.

\section{Correspondence}

Lisa Calvocoressi, Ph.D., Yale University School of Public Health, Yale University School of Medicine: lisa.calvocoressi@yale.edu. 


\title{
FAMILY ACCOMMODATION SCALE FOR OBSESSIVE-COMPULSIVE DISORDER Interviewer-Rated (FAS-IR)
}

\author{
Developed by \\ Lisa Calvocoressi, Ph.D., Carolyn M. Mazure, Ph.D., Barbara Van Noppen, Ph.D., and
}

Lawrence H. Price, M.D.

\section{GENERAL INFORMATION AND INSTRUCTIONS FOR ADMINISTERING THE FAMILY ACCOMMODATION SCALE FOR OBSESSIVE-COMPULSIVE DISORDER}

The Family Accommodation Scale for Obsessive-Compulsive Disorder assesses the extent to which relatives of patients with OCD engage in 12 types of accommodating behaviors. The FAS-IR is a semi-structured interview administered by a clinician or trained lay interviewer. Questions and statements read aloud to the family member by the interviewer are enclosed in quotation marks. Instructions for the interviewer are written in italics.

The FAS includes two areas of inquiry. First, the interviewer obtains information from the family member regarding the patient's current symptoms. Second, the interviewer assesses the extent to which the family member is involved in accommodating the patient's symptoms. Each item includes common examples of accommodating behaviors, but the interviewer may wish to develop additional examples based on information gleaned form the family member's report of patient symptoms.

Each item is scored on a scale ranging from 0 (i.e., None/Not at all) to 4 (i.e., Everyday/Extreme). Total FAS scores range from 0 to 48 and are obtained by summing the item scores. A scoring sheet is included (p. 15). 


\title{
FAMILY ACCOMMODATION SCALE FOR OBSESSIVE-COMPULSIVE DISORDER Interviewer-Rated (FAS-IR)
}

\author{
Developed by \\ Lisa Calvocoressi, Ph.D., Carolyn M. Mazure, Ph.D., Barbara Van Noppen, Ph.D., and \\ Lawrence H. Price, M.D.
}

Relative to Subject ID\#:

Date:

Interviewer:

INTRODUCTION AND GENERAL INSTRUCTIONS FOR THE FAMILY MEMBER: "The purpose of this interview is to learn about the ways in which you may be modifying your behavior or routines to accommodate (name of patient)'s symptoms. During this interview, I will first ask you about the obsessive-compulsive symptoms that (name of patient) has been experiencing, and then I will ask you about the ways in which you have responded to these symptoms. This interview will last about 30 minutes. If, at any time, you are uncertain about what I am asking, please let me know and I will try to clarify the question for you."

\section{FAMILY MEMBER'S REPORT OF PATIENT'S SYMPTOMS}

INSTRUCTIONS FOR THE FAMILY MEMBER: "I will define obsessions, compulsions, and other symptoms related to $O C D$, and ask you if (name of patient) has experienced any of these symptoms during the past week."

(Read the description of each symptom, check all that apply, and then ask the family member to describe the patient's specific symptoms. Record specific symptoms on the sheet entitled

PATIENT SYMPTOM LIST (p. 4))

\section{OBSESSIONS}

"Obsessions are distressing ideas, thoughts, images or impulses that repeatedly enter a person's mind and may seem to occur against his or her will. The thoughts may be repugnant or frightening, or may seem senseless to the person who is experiencing them."

"I will now review a list of different types of obsessions common in OCD. Please tell me if (name of patient) has experienced any of these obsessions during the past week."

\section{HARMING OBSESSIONS}

"During the past week, has (name of patient) experienced obsessions involving fears of harming self or others, stealing things, blurting out obscenities or insults, acting on unwanted impulses, or doing something else embarrassing? Has (name of patient) had fears associated with being responsible for something terrible happening, such as a fire or burglary, or has s/he complained of experiencing violent or horrific images?" 


\section{CONTAMINATION OBSESSIONS}

"During the past week, has (name of patient) experienced excessive concerns about or disgust with bodily waste or secretions, dirt, or germs? Has s/he had excessive concerns about contamination due to environmental toxins, for example, asbestos, radiation, or toxic waste? Has (name of patient) feared contamination due to household cleansers or solvents, or to animals, such as insects? Has s/he experienced discomfort with sticky substances or residues, feared illness because of a contaminant, or been concerned about contaminating others?"

\section{SEXUAL OBSESSIONS}

"During the past week, has (name of patient) experienced obsessions concerning forbidden or improper sexual thoughts, images, or impulses, or has $\mathrm{s}$ /he had repeated thoughts of incest, sexual involvement with children, or aggressive sexual behavior toward others?"

\section{SAVING/LOSING OBSESSIONS}

"During the past week, has (name of patient) experienced obsessions related to saving things or an unfounded fear of losing something valuable?"

\section{RELIGIOUS OBSESSIONS}

"During the past week, has (name of patient) experienced obsessions involving irreverent, sacrilegious, or blasphemous thoughts? Has s/he had excessive concerns about right and wrong?"

\section{OBSESSION WITH NEED FOR SYMMETRY OR EXACTNESS}

"During the past week, has (name of patient) experienced obsessions related to a need for things to be symmetrical or in exactly the right place? Does s/he insist that certain items not be moved or touched (e.g., must have canned goods lined up or clothes organized alphabetically)?"

\section{SOMATIC OBSESSIONS}

"During the past week, has (name of patient) experienced excessive concerns about illness or disease (such as AIDS or cancer)?"

\section{MISCELLANEOUS OBSESSIONS}

"During the past week, has (name of patient) evidenced an excessive need to know or remember, a fear of losing things, obsessions regarding saying certain things or not saying just the right thing, a discomfort with certain sounds or noises, or has s/he had repeated thoughts of lucky or unlucky numbers?" 


\section{COMPULSIONS}

"Compulsions are defined as behaviors or acts that a person feels driven to perform, although s/he may recognize them as senseless or excessive. It may be difficult or anxiety provoking for a person to resist performing these behaviors."

"I will now review a list of different types of compulsions common in OCD. Please tell me if (name of patient) has experienced any of these compulsions during the past week."

\section{CLEANING/WASHING COMPULSIONS}

"During the past week, has (name of patient) engaged in excessive or ritualized hand washing, showering, bathing, tooth brushing, grooming, or toilet routine? Has s/he engaged in excessive cleaning of household items or other inanimate objects, or pursued other measures to remove or prevent contact with contaminants?"

\section{CHECKING COMPULSIONS}

"During the past week, has (name of patient) excessively checked locks, stove, appliances or other items? Has $s /$ he engaged in checking to ensure that $s /$ he did not or will not harm self or others, that nothing terrible did or will happen, or that $\mathrm{s} /$ he did not make a mistake? Has (name of patient) engaged in checking tied to fears of illness or contamination?"

\section{REPEATING RITUALS}

"During the past week, has (name of patient) had to re-read or re-write things, or has s/he repeated routine activities, for example, getting up and down from a chair?"

\section{COUNTING COMPULSIONS}

"During the past week, has (name of patient) engaged in compulsions involving counting things (e.g., counting floor tiles, books on a shelf, or words in a sentence)?"

\section{ORDERING/ARRANGING COMPULSIONS}

"During the past week, has (name of patient) engaged in compulsions involving ordering or arranging things? This includes excessive straightening of papers on a desk, adjusting furniture or picture frames."

\section{SAVING/COLLECTING COMPULSIONS}

"During the past week, has (name of patient) engaged in compulsions involving saving (such as old newspapers or junk mail) or collecting things?" 


\section{MISCELLANEOUS COMPULSIONS}

"During the past week, has (name of patient) engaged in mental rituals, excessive list making, measures to prevent harm to self or others, or to prevent terrible consequences, or has $\mathrm{s} /$ he evidenced a need to tell, ask, or confess?"

\section{OTHER OCD-RELATED PROBLEMS}

"During the past week, has (name of patient) avoided doing things, going places or being with people because of obsessional thoughts or out of concern that $s /$ he might perform compulsions?"

\section{INDECISIVENESS}

"During the past week, has (name of patient) had difficulty making decisions about things that other people might not think twice about; for example, which clothes to put on in the morning or which brand of cereal to buy?"

\section{OVERVALUED SENSE OF RESPONSIBILITY}

"A person with OCD may feel very responsible for the consequences of his/her actions and assume blame for the outcome of events not completely in his/her control. Has (name of patient) exhibited such an overly strong sense of responsibility during the past week?"

\section{PERVASIVE SLOWNESS/ DISTURBANCE OF INERTIA}

"Some patients with OCD have difficulty starting or finishing tasks. Many routine activities take longer than they should. Has (name of patient) had such difficulties with any routine tasks during the past week?"

\section{PATHOLOGICAL DOUBTING}

"Some patients with OCD doubt whether they have performed an activity correctly, or whether they did it at all. When carrying out routine activities they may find that they don't trust their senses; that is, what they see, hear, or touch. Has (name of patient) exhibited such doubting during the past week?" 
The Case of "Brianne" and "Charlie"

J. Marinchak

Pragmatic Case Studies in Psychotherapy, http://pcsp.libraries.rutgers.edu

Volume 9, Module 1, Article 1, pp. 1-57, 02-17-13 [copyright by author]

\section{PATIENT SYMPTOM LIST}

(Describe symptoms reported by the family member and refer to this list when posing the remaining questions.)

\section{OBSESSIONS}

1.

2.

3.

4.

5.

6.

COMPULSIONS

1.

2.

3.

4.

5.

6.

\section{$\underline{\text { OTHER }}$ OCD-RELATED PROBLEMS}

1.

2.

3.

4.

5.

6. 


\section{FAMILY MEMBER'S REPORT OF ACCOMMODATING BEHAVIORS}

INSTRUCTIONS FOR THE FAMILY MEMBER: "You have told me that (name of patient) has the following symptoms (review patient symptom list). I am now going to ask you about ways in which you may have responded to (name of patient) and his/her symptoms during the past week.".(Formulate examples of accommodation for each question using the specific symptoms on the Patient Symptom List.)

\section{PROVIDING REASSURANCE}

"During the past week, when (name of patient) has expressed worries, fears, or doubts related to obsessions or compulsions, have you reassured him/her that s/he doesn't have to worry, that there are no grounds for his/her concerns, or that the rituals $s /$ he already performed have taken care of his/her concerns? Examples might include telling your relative that $\mathrm{s} / \mathrm{he}$ is not contaminated, or that $\mathrm{s} / \mathrm{he}$ has done enough cleaning or checking."

"During the past week, on how many occasions did you provide reassurance to (name of patient) that was directly related to an obsession or compulsion? [Do not include instances in which you provided more general reassurance that $s /$ he will overcome her symptoms or feel better soon, or reassurance about matters unrelated to OCD.]"

$\mathrm{N} / \mathrm{A}=$ Not applicable. Patient did not experience $\mathrm{OCD}$ symptoms this week. $0=$ None

$1=1 /$ week

$2=2-3 /$ week

$3=4-6 /$ week

4 = Everyday

\section{WATCHING THE PATIENT COMPLETE RITUALS}

"During the past week, did you deliberately watch (name of patient) complete rituals at his/her request or because you thought s/he would want you to do so?"

"During the past week, how many times did you watch (name of patient) complete rituals? [Do not include those instances in which you just happened to see him/her performing rituals.]"

$\mathrm{N} / \mathrm{A}=$ Not applicable. Patient did not experience $\mathrm{OCD}$ symptoms this week. $0=$ None

$1=1 /$ week

$2=2-3 /$ week

$3=4-6 /$ week

4 = Everyday 


\section{WAITING FOR THE PATIENT}

"During the past week, did you wait for (name of patient) to complete compulsive behaviors, resulting in interference with plans you had made?"

"During the past week, how many times did you wait for (name of patient) because of his/her OCD?"

$\mathrm{N} / \mathrm{A}=$ Not applicable. Patient did not experience $\mathrm{OCD}$ symptoms this week. $0=$ None

$1=1 /$ week

$2=2-3 /$ week

$3=4-6 /$ week

4 = Everyday

\section{REFRAINING FROM SAYING/DOING THINGS}

"During the past week, were there things that you did not do or say because of (name of patient)'s OCD? For example, family members may stop themselves from entering some areas of the house, refrain from physical contact with the relative with $O C D$, or avoid conversation topics related to the relative's obsessions."

"During the past week, how often did you stop yourself from saying or doing things because of (name of patient)'s OCD?"

$\mathrm{N} / \mathrm{A}=$ Not applicable. Patient did not experience $\mathrm{OCD}$ symptoms this week. $0=$ None

$1=1 /$ week

$2=2-3 /$ week

$3=4-6 /$ week

4 = Everyday

\section{PARTICIPATING IN COMPULSIONS}

"During the past week, did you engage in (name of patient)'s compulsions or in behaviors which you consider odd or senseless at his/her request, or because you thought (name of patient) would want you to do these things? For example, family members might wash their hands more times than they feel is necessary (or in a ritualized way) or they may check the burners on the stove repeatedly even though they believe the burners are not lit."

"During the past week, how many times did you directly participate in (name of patient)'s rituals or in behaviors that you consider odd or senseless?"

$\mathrm{N} / \mathrm{A}=$ Not applicable. Patient did not experience $\mathrm{OCD}$ symptoms this week. $0=$ None

$1=1 /$ week 
$2=2-3 /$ week

$3=4-6 /$ week

4 = Everyday

\section{FACILITATING COMPULSIONS}

"Were there times in this past week in which your actions made it possible for (name of patient) to complete his/her rituals (without you being directly involved in performing the rituals)? For example, a family member may provide a relative with OCD with things $s /$ he needs to perform rituals or compulsions, such as buying excessive quantities of soap or cleaning products. Other examples include driving the car back to the house so the relative can check that doors are locked, or creating extra space in the house for the relative's saved items."

"During the past week, how many times did you do something that helped (name of patient) complete rituals? [Do not include those instances in which you directly participated in rituals as noted in the last question (item 5).]"

$\mathrm{N} / \mathrm{A}=$ Not applicable. Patient did not experience $\mathrm{OCD}$ symptoms this week. $0=$ None

$1=1 /$ week

$2=2-3 /$ week

$3=4-6 /$ week

4 = Everyday

\section{FACILITATING AVOIDANCE}

"In the past week, did you get involved in (name of patient)'s efforts to avoid people, places, or things? Or did you do anything that allowed him/her avoid? For example, family members may make excuses for a relative who says s/he cannot attend a social function because of OCD-related concerns, take a roundabout driving route because the relative wants to avoid a 'contaminated' area, or open a door so the relative does not have to touch a "contaminated" door handle."

"During the past week, on how many occasions did you do something that helped (name of patient) avoid people, places, or things? [Do not include instances in which you participated in compulsions or did something that helped your relative to complete compulsions, as noted in the last two questions (items 5 and 6).]"

$\mathrm{N} / \mathrm{A}=$ Not applicable. Patient did not experience $\mathrm{OCD}$ symptoms this week. $0=$ None

$1=1 /$ week

$2=2-3 /$ week

$3=4-6 /$ week

4 = Everyday 


\section{TOLERATING ODD BEHAVIORS/HOUSEHOLD DISRUPTION}

"During the past week, did you put up with odd behaviors on (name of patient)'s part (e.g., repetitive actions such as going in and out of a doorway), or did you put up with unusual conditions in your home because of (name of patient)'s OCD; for example leaving the home cluttered with old newspapers or ignoring repeated closing and opening of doors?"

"During the past week, to what extent did you tolerate odd behaviors or unusual conditions in your home because of (name of patient)'s OCD? [This question is specific to behaviors or conditions that you allow to occur. Do not include instances in which you took action to participate in or facilitate compulsions or avoidance noted under the last three questions (items 5-7).]" (RATER SCORED)

$\mathrm{N} / \mathrm{A}=$ Not applicable. Patient did not experience OCD symptoms this week.

$0 \quad=$ Not at all.

$1=$ Mild; tolerated slightly unusual behavior/conditions.

2 = Moderate; tolerated behavior/conditions that are somewhat unusual.

3 = Severe; tolerated very unusual behavior/conditions.

4 = Extreme; tolerated extremely aberrant behavior/conditions.

9. HELPING THE PATIENT WITH TASKS OF DAILY LIVING OR SIMPLE DECISIONS "During the past week, did you help (name of patient) complete simple tasks of daily living or make simple decisions when his/her ability to function was impaired by OCD; for example, helping him/her to get dressed, to bathe, or to decide what to eat?"

"During the past week, on how many occasions did you help (name of patient) with simple tasks or decisions because $s /$ he was impaired by OCD? [Do not include instances or in which doing a task for your relative included doing something that helped him/her avoid an OCD-related fear (item 7) or in which making a decision for your relative consisted of providing reassurance about an OCD-related concern (item 1).]"

$\mathrm{N} / \mathrm{A}=$ Not applicable. Patient did not experience $\mathrm{OCD}$ symptoms this week. $0=$ None

$1=1 /$ week

$2=2-3 /$ week

$3=4-6 /$ week

4 = Everyday

10. TAKING ON PATIENT'S RESPONSIBILITIES

“Do you take on tasks that are (name of patient)'s responsibility but which he/she cannot adequately perform because of his/her OCD? Examples include paying his/her bills, or taking care of his/her children."

"During the past week, to what extent did you take on (name of patient)'s responsibilities due to 
OCD? [Do not include doing simple tasks of daily living for your relative, as noted under the last question (item 9).]" (RATER SCORED)

$\mathrm{N} / \mathrm{A}=$ Not applicable. Patient did not experience OCD symptoms this week.

$0=$ Not at all.

1 = Mild; occasionally handles one of patient's responsibilities, but there has been no substantial change in his/her role.

2 = Moderate; has assumed patient's responsibilities in one area.

3 = Severe; has assumed patient's responsibilities in more than one area.

4 = Extreme; has assumed most or all of patient's responsibilities. 


\section{MODIFYING YOUR PERSONAL ROUTINE}

"Are you currently modifying your leisure time activities, or your work or family responsibilities, because of (name of patient)'s OCD? Examples of modifying one's personal routine might include spending less time socializing or exercising, or changing one's work schedule to spend more time attending to the person with OCD."

"During the past week, to what extent did you modify your personal routine because of (name of patient)'s OCD?" (RATER SCORED)

N/A = Not applicable. Patient did not experience OCD symptoms this week.

$0 \quad=$ Not at all.

1 = Mild; slightly modified routine, but was able to fulfill family and/or work responsibilities and to engage in leisure time activities.

2 = Moderate; definitely modified routine in one area (family, work, or leisure time).

3 = Severe; definitely modified routine in more than one area.

4 = Extreme; unable to attend to work or family responsibilities or to have any leisure time because of relative's OCD.

\section{MODIFYING THE FAMILY ROUTINE}

"Are you currently modifying what you consider an ordinary family routine because of (name of patient)'s OCD? Examples might include modifying the family's cooking or cleaning practices."

"During the past week, to what extent did you modify the family routine because of (name of patient)'s OCD? To what degree has your relative's OCD necessitated changes in family activities or practices?" (RATER SCORED)

$\mathrm{N} / \mathrm{A}=$ Not applicable. Patient did not experience OCD symptoms this week.

$0=$ Not at all.

1 = Mild. The family routine was slightly modified, but remained substantially unchanged.

2 = Moderate. The family routine was definitely modified in one area.

3 = Severe. The family routine was definitely modified in more than one area.

4 = Extreme. The family routine was disrupted in most or all areas. 


\section{Scoring Sheet \\ Family Accommodation Scale for Obsessive-Compulsive Disorder Interviewer-Rated (FAS-IR)}

Subject:

Total Score:
Interviewer:

Date:

\begin{tabular}{|c|c|c|c|c|c|c|}
\hline & $\mathrm{N} / \mathrm{A}$ & None & Mild & Moderate & Severe & Extreme \\
\hline Item 1: Providing Reassurance & 0 & 0 & 1 & 2 & 3 & 4 \\
\hline $\begin{array}{l}\text { Item 2: Watching the Patient Complete } \\
\text { Rituals }\end{array}$ & 0 & 0 & 1 & 2 & 3 & 4 \\
\hline Item 3: Waiting for the Patient & 0 & 0 & 1 & 2 & 3 & 4 \\
\hline $\begin{array}{l}\text { Item 4: Refraining From Saying/Doing } \\
\text { Things }\end{array}$ & 0 & 0 & 1 & 2 & 3 & 4 \\
\hline Item 5: Participating in Compulsions & 0 & 0 & 1 & 2 & 3 & 4 \\
\hline Item 6: Facilitating Compulsions & 0 & 0 & 1 & 2 & 3 & 4 \\
\hline Item 7: Facilitating Avoidance & 0 & 0 & 1 & 2 & 3 & 4 \\
\hline $\begin{array}{l}\text { Item 8: Tolerating Odd Behavior/ } \\
\text { Household Disruption }\end{array}$ & 0 & 0 & 1 & 2 & 3 & 4 \\
\hline Item 9: Helping with Simple Tasks & 0 & 0 & 1 & 2 & 3 & 4 \\
\hline $\begin{array}{l}\text { Item 10: Taking on Patient's } \\
\text { Responsibilities }\end{array}$ & 0 & 0 & 1 & 2 & 3 & 4 \\
\hline Item 11: Modifying Personal Routine & 0 & 0 & 1 & 2 & 3 & 4 \\
\hline Item 12: Modifying Family Routine & 0 & 0 & 1 & 2 & 3 & 4 \\
\hline
\end{tabular}

(Sum item scores to obtain total score.)

COPYRIGHT (C 1999 by Lisa Calvocoressi, Ph.D., Carolyn M. Mazure, Ph.D., Barbara Van Noppen, Ph.D., and Lawrence H. Price, M.D. 